\title{
Oil Exports and the Iranian Economy
}

\author{
Hadi Salehi Esfahani, Kamiar Mohaddes \\ and M. Hashem Pesaran
}

October 2009

CWPE 0944 


\title{
Oil Exports and the Iranian Economy
}

\author{
Hadi Salehi Esfahani ${ }^{\dagger}$, Kamiar Mohaddes ${ }^{\ddagger}$, and M. Hashem Pesaran ${ }^{\ddagger \top}$ \\ ${ }^{\dagger}$ Department of Economics, University of Illinois \\ $\ddagger$ Faculty of Economics, University of Cambridge \\ ${ }^{\top}$ Department of Economics, University of Southern California
}

October 8, 2009

\begin{abstract}
This paper develops a long run growth model for a major oil exporting economy and derives conditions under which oil revenues are likely to have a lasting impact. This approach contrasts with the standard literature on the "Dutch disease" and the "resource curse", which primarily focus on short run implications of a temporary resource discovery. Under certain regularity conditions and assuming a Cobb Douglas production function, it is shown that (log) oil exports enter the long run output equation with a coefficient equal to the share of capital. The long run theory is tested using a new quarterly data set on the Iranain economy over the period 1979Q1-2006Q4. Building an error correction specification in real output, real money balances, inflation, real exchange rate, oil exports, and foreign real output, the paper finds clear evidence for two long run relations: an output equation as predicted by the theory and a standard real money demand equation with inflation acting as a proxy for the (missing) market interest rate. Real output in the long run is shaped by oil exports through their impact on capital accumulation, and the foreign output as the main channel of technological transfer. The results also show a significant negative long run association between inflation and real GDP, which is suggestive of economic inefficiencies. Once the effects of oil exports are taken into account, the estimates support output growth convergence between Iran and the rest of the world. We also find that the Iranian economy adjusts quite quickly to the shocks in foreign output and oil exports, which could be partly due to the relatively underdeveloped nature of Iran's financial markets.
\end{abstract}

JEL Classifications: C32, C53, E17, F43, F47, Q32.

Keywords: Growth models, long run relations, Iranian economy, oil price and foreign output shocks, and error correcting relations. 


\section{Introduction}

In this paper we develop a long run output relation for a major oil exporting economy where oil income to output ratio is expected to remain high over a prolonged period. This approach contrasts with the 'Dutch disease' and 'resource curse' literature that considers the revenues from the resource to be intrinsically temporary and focusses on the relatively short term implications of the resource discovery. See Corden and Neary (1982), Krugman (1987), Neary and van Wijnbergen (1986), and van der Ploeg and Venables (2009) for a recent survey. We extend the stochastic growth model developed in Binder and Pesaran (1999) to allow for the possibility that a certain fraction of oil export revenues is invested in the domestic economy. We distinguish between the two cases where the growth of oil income, $g^{0}$, is less than the natural growth rate (the sum of the population growth, $n$, and the growth of technical progress) and when $g^{0} \geq g+n$. Under the former, the effects of oil income on the economy's steady growth rate will vanish eventually, whilst under the latter, oil income enters the long run output equation with a coefficient which is equal to the share of capital if it is further assumed that the underlying production technology can be represented as a Cobb-Douglas production function.

The empirical validity of the long run output equation for the Iranian economy is examined by incorporating it into a vector autoregressive error correction model augmented with foreign output. The resultant VARX* model is estimated using quarterly observations over the period 1979Q1-2006Q4. The domestic variables included in the model are real GDP, the rate of inflation based on consumer price index (CPI), the official and 'free' market exchange rates, and money and quasi money. Unlike most other macro models, ours does not include the interest rate as an explicit variable because the domestic credit markets in Iran operate under tight controls and the interest rate is not market-determined. But assuming that the Fisher equation holds in the long run, the inflation rate can be used as a proxy for the interest rate. The foreign output variable is constructed as a weighted average of the log output of Iran's trading partners with the weights based on the relative size of their trade with Iran (exports plus imports).

A number of models of Iran's macroeconomy have been developed in the past. The distinctive features of our model are: (1) a theory derived long run model for oil exporting countries in which the long run role of oil export revenues for growth is explicitly modeled; (2) a careful and parsimonious modeling of the ways in which major external variables enter into the macroeconomic equations in Iran, taking into account the variety of channels through which the variables influence each other, including the implicit response of the government to macroeconomic developments; (3) parameterization of the model to allow for the measurement and testing of the macro-level impact of oil exports and global technological progress on the Iranian economy; (4) joint modeling and estimation of output, inflation, money supply, and the real exchange rate, in contrast to models that focus on output or inflation alone, while treating the other variables as exogenous; and (5) use of quarterly data.

The maximum likelihood estimates of the VARX* model support the existence of two long run relations, namely the real output and the real money demand equations, as predicted by the theory. Furthermore, it is not possible to reject the hypothesis that real output, real money balances, real oil income, and foreign output are co-trending. The evidence also supports the existence of a long run relation between domestic output, foreign output, and 
real oil exports, although we also find that inflation has a statistically significant negative effect on real output. Once the effects of oil exports are taken into account, the estimates support output growth convergence between Iran and the rest of the world. These results seem to be reasonably robust regardless of how foreign output is constructed, what measure of the exchange rate is used, and whether a dummy variable for revolution and war (over the period 1979Q1-1988Q2) is included in the model.

From the estimates, several conclusions can be drawn. One key result is the economy's fast adjustment to shocks, when compared to the response rates of other economies, especially the developed ones. This seems to be due to the limitations of Iran's financial markets that restrict expenditure smoothing options and thereby cause the economy to move up and down quickly as external and internal conditions change. Second, we find that although Iran may lag behind its main trading partners in terms of technology levels, it has experienced a similar rate of technological progress over the past three decades. Third, in the long run, oil exports contribute to real income through real capital accumulation. As a result, the elasticity of the aggregate real income with respect to real oil revenues (measured in term of domestic output units) is equal to the marginal product of capital. We confirm this result by showing that the nominal dollar value of oil revenues has the same impact on the real GDP as would be caused by a decline in the dollar value of one unit of domestic output. Fourth, our estimates suggest that in Iran, the output elasticity of capital (or the share of capital) is about 0.26. This estimate is lower than the one often used in studies of Iran's economy. But, it seems quite reasonable given the large resource rents that can be channeled towards investment. Fifth, there is a significant negative association between inflation and real GDP. This implies that inflation in Iran is largely driven by long-term adverse shocks to the economy. Of course, to the extent that inflation is driven exogenously by expansionary macroeconomic policies, it could have major negative effects on output. Sixth, in the long run, the elasticity of real money balances with respect to the real output is around unity, and inflation (used as a proxy for interest rate) has a negative effect on real money balances.

The rest of the paper is set out as follows. Section 2 develops a long run macroeconomic model for an oil exporting economy and discusses the long run restrictions applicable to oil exporters. Section 3 discusses the main macroeconomic trends in post-revolutionary Iran. Section 4 describes the VARX* econometric model that embodies the long run relations. Section 5 presents the long run estimates and the various tests of the long run theory. Section 6 discusses the short run dynamics and provides evidence on speed of convergence to equilibrium, impulse responses, and error correction estimates. Section 7 concludes.

A review of earlier work on macroeconomic models for Iran is provided in Appendix A. This review is intended to place our modelling work in the context of the existing literature. Data sources and computation of foreign output are described in Appendix B, and the results of unit root tests are given in Appendix C.

\section{A Theory of Economic Growth for a Major Oil Ex- porter}

Most papers in the growth literature do not include natural resource abundant economies, in particular, oil exporting countries, in their cross-country empirical analysis. The literature 
that specifically deals with resource abundant economies tends to focus on short term effects, and given the depletable nature of the resource, the revenues that flow from it are viewed as "intrinsically temporary" (van der Ploeg and Venables (2009)). A number of early studies also considered the macroeconomic effects of the resource discovery and focussed on the "Dutch disease" phenomenon first experienced in Netherlands after the large, but shortlived, discovery of gas in 1960s. See, for example, Corden and Neary (1982), Krugman (1987), and Neary and van Wijnbergen (1986) among others.

Dutch disease postulates that an exogenous unexpected increase in foreign exchange revenues from the resource, due to rising prices or output, will result in real exchange rate appreciation and a fall in output and employment of the non-resource traded goods sector, often manufacturing. This by itself need not have adverse long run implications for the economy as a whole. One would expect the economy to re-adjust once the revenues from the resource are diminished or vanish altogether, unless there are important non-convexities or imperfections in the economy. For example, if the manufacturing sector is subject to economies of scale or learning by doing, the loss of manufacturing capacity will be very costly to reverse.

The more recent literature on resource abundance and economic growth focusses on the political economy considerations and argues that large windfalls from the resource create incentives for the rent-seeking activities that involve corruption (Mauro (1995) and Leite and Weidmann (1999)), voracity (Lane and Tornell (1996) and Tornell and Lane (1999)), and possibly civil conflicts (Collier and Hoeffler (2004)). ${ }^{1}$ Some of these considerations have been recently formalized by Caselli and Cunningham (2009) where they attempt to characterize conditions under which an increase in the size of the resource rent leads to a decrease in real output, the so called "natural resource curse" hypothesis. Empirical support for this hypothesis was originally provided by Sachs and Warner (1995) who showed the existence of a negative relationship between real GDP growth per capita and different measures of resource abundance, such as the ratio of resource exports to GDP. ${ }^{2}$ The finding that resource rich countries tend to perform poorly when compared to economies that are not well endowed with natural resources is clearly paradoxical and require further explanations and naturally has led to a growing empirical literature.

Most papers in the resource curse literature tend to follow Sachs and Warner's crosssectional specification introducing new explanatory variables, while others derive theoretical models that are loosely related to their empirical specification. Some of these papers confirm Sachs and Warner's results, but there is an emerging literature, including Brunnschweiler and Bulte (2008), which argues that the so-called resource curse paradox does not exist, and that while resource dependence does not affect growth, resource abundance in fact positively affects growth. Thus, from the empirical literature, there is no clear cut answer to whether natural resource abundance is a blessing or a curse. The recent theoretical work of Caselli and Cunningham (2009) is not conclusive either and, perhaps not surprisingly, can yield outcomes that are not compatible with the resource curse hypothesis.

While in the short run we would expect that an increase in oil export revenues would put

\footnotetext{
${ }^{1}$ For early contributions on the importance of rent seeking in oil exporting economies see Mahdavi (1970) and Pesaran (1982)

${ }^{2}$ See also Sachs and Warner (1997) and Sachs and Warner (2001)
} 
pressure on the real exchange rate, the Dutch disease channel will only harm an economy in the long run if these oil revenues are short-lived or subject to such volatility that in some periods oil export revenues are negligible while in other periods they are prominent. For major oil exporting countries, of which many started oil extraction and exports in the beginning of the 20th century, the reserve-to-extraction ratio indicates that they are capable of producing for many more decades even in the absence of new oil field discoveries or major advances in oil exploration and extraction technologies.

\section{Figure 1: Oil export revenues to income ratios for major oil exporters}

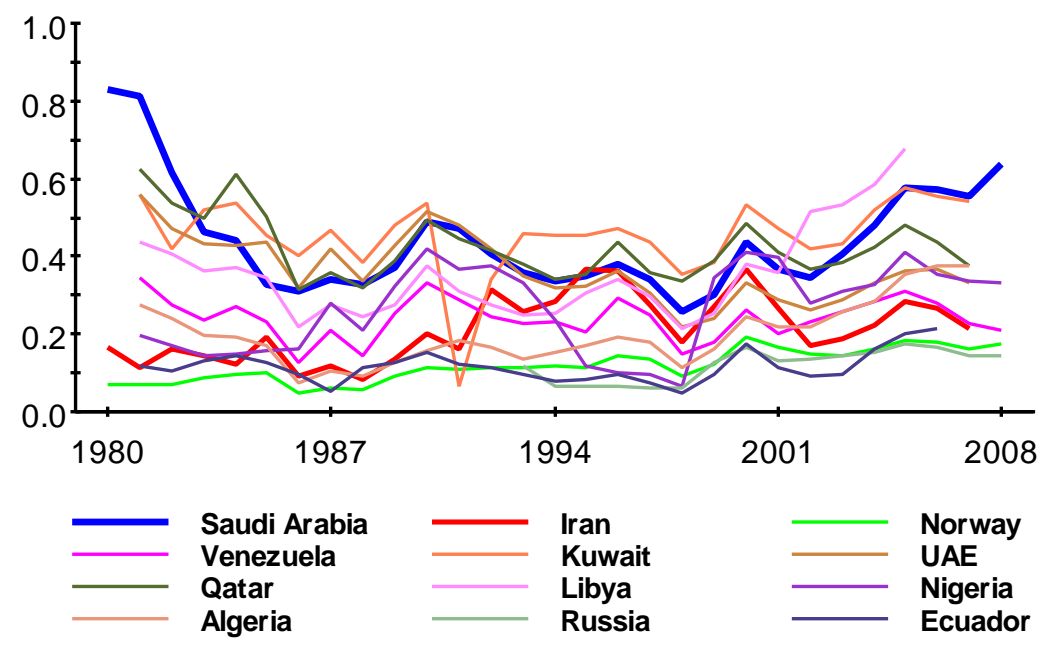

In the case of Iran, the first major oil field was discovered in 1908 with oil production started flowing in sizeable amounts in 1912. Even after 100 years of exploration and production, Iran's current estimated reserve-to-extraction ratio suggests a further 87 years of oil production. In addition, Iran has the second largest natural gas reserves after Russia, around 60 percent of which is yet to be developed. ${ }^{3}$ Although, it is clear that Iran's oil and gas reserves will be exhausted eventually, this is likely to take place over a relatively long period. In fact over the past two decades the ratio of Iran's oil export revenues to GDP has fluctuated around 26 percent and currently stands at 21.5 percent. Of course, Iran is not unique in this regard. As Figure 1 shows most other OPEC (Organization of the Petroleum Exporting Countries) member countries such as Saudi Arabia, Venezuela, Nigeria, Algeria, United Arab Emirates and Kuwait, and a few countries outside OPEC such as Norway and Russia have similar oil income GDP ratios that have remained relatively stable (and in some cases have even been rising as in Norway). There is little evidence to suggest that in these economies oil income will be diminishing any time soon.

To summarize, most macroeconomic analysis of oil revenues tend to take a short term perspective. They usually focus on the effects of oil revenues on the real exchange rate (Dutch disease) and government budget expansion, thus failing to consider the effects of oil revenues

\footnotetext{
${ }^{3}$ See, for example, Amuzegar (2008) and BP (2009).
} 
on long run growth. This approach makes sense for countries with a limited amount of oil reserves, but not for major oil exporting countries such as Iran. Therefore, the aim of this section is to develop a long run theory for oil exporters in which oil export revenues affect the growth rate of income in the long run. In this process rent-seeking and other political economy considerations are clearly still important, and tend to manifest themselves in the equilibrium level of capital stock and can influence the steady state growth of the economy. However, such political economy considerations will not be addressed in this paper.

\subsection{Long Run Output Equation for Oil Exporting Economies}

Consider an oil exporting economy with a constant return to scale production function in labour, $L_{t}$, and capital stock, $K_{t}$ :

$$
Y_{t}=A_{t} L_{t} f\left(\frac{K_{t}}{A_{t} L_{t}}\right)
$$

where $Y_{t}$ is the real output and $A_{t}$ is an index of labour augmented technological progress. Following the literature it will be assumed that $A_{t}$ and $L_{t}$ are exogenously given and follow general linear processes defined by

$$
\log \left(A_{t}\right)=a_{0}+g t+u_{a t}
$$

and

$$
\log \left(L_{t}\right)=l_{0}+n t+u_{l t}
$$

where $a_{0}$ and $l_{0}$ are economy-specific initial endowments of technology and labour, $g$ and $n$ are the steady state growth rates of technology and labour input respectively, and $u_{a t}$ and $u_{l t}$ follow general linear processes possibly with unit roots.

Denote by $X_{t}$ the real value of (net) oil exports

$$
X_{t}=\frac{E_{t} P_{t}^{o} X_{t}^{o}}{P_{t}}
$$

where $P_{t}^{o}$ is the price of oil per barrel in US dollar, $X_{t}^{o}$ is the total number of barrels of oil exports, $E_{t}$ is the exchange rate in terms of US dollar, and $P_{t}$ is the consumer price index. Note that we could also include oil as an input in the production process but we abstract from this to simplify the analysis. Let $\kappa_{t}$ be the value of capital in terms of effective labour input:

$$
\kappa_{t}=\frac{K_{t}}{A_{t} L_{t}}
$$

and $\chi_{t}$ denote the value of real oil exports in terms of effective units of labour input:

$$
\chi_{t}=\frac{X_{t}}{A_{t} L_{t}}
$$

Then the capital accumulation equation can be written as

$$
K_{t+1}=(1-\delta) K_{t}+s\left(\boldsymbol{\zeta}_{t}\right) Y_{t}+\lambda\left(\boldsymbol{\zeta}_{t}\right) X_{t}
$$


where $\delta$ is the rate of depreciation $(0<\delta<1), s\left(\boldsymbol{\zeta}_{t}\right)$ and $\lambda\left(\boldsymbol{\zeta}_{t}\right)$ are the shares of non-oil output and (net) oil income that are invested and $\boldsymbol{\zeta}_{t}=\left(\kappa_{t}, \chi_{t}\right)^{\prime}$ is the vector of state variables. It is assumed that $s\left(\boldsymbol{\zeta}_{t}\right)$ and $\lambda\left(\boldsymbol{\zeta}_{t}\right)$ lie in the range $(0,1)$, and oil is produced without the use of domestic resources.

Using (2) and (3), the general specification for $\ln \left(A_{t} L_{t}\right)$ is given by:

$$
\ln \left(A_{t} L_{t}\right)=a_{0}+l_{0}+(g+n) t+u_{t}
$$

where $u_{t}=u_{a t}+u_{l t}$. Hence

$$
\Delta \ln \left(A_{t+1} L_{t+1}\right)=g+n+\Delta u_{t+1}
$$

Using (8) we can write the capital accumulation equation given in (7) in terms of effective labour units:

$$
\kappa_{t+1}=\left[(1-\delta) \kappa_{t}+s\left(\boldsymbol{\zeta}_{t}\right) f\left(\kappa_{t}\right)+\lambda\left(\boldsymbol{\zeta}_{t}\right) \chi_{t}\right] \exp \left(-g-n-\Delta u_{t+1}\right) .
$$

Note that $\Delta u_{t+1}$ is a stationary process irrespective of whether the processes for $A_{t}$ or $L_{t}$ have unit roots. The presence of a unit root in $A_{t}$ is, however, essential if log per capita output is to have a unit root, a hypothesis that cannot be rejected when tested using historical output series.

To solve for $\kappa_{t}$, the process for real oil revenues must also be specified. Given that oil revenues are dominated by oil price movements and the latter is best approximated by a random walk model with a drift, we assume that

$$
\Delta \log \left(X_{t+1}\right)=g^{o}+\Delta v_{t+1}
$$

where $g^{o}$ is the drift coefficient, and $v_{t} \sim \operatorname{iid}\left(0, \sigma_{v}^{2}\right)$. Given (8) and (10) we have:

$$
\begin{aligned}
\Delta \log \left(\chi_{t+1}\right) & =g^{o}+\Delta v_{t+1}-\left(g+n+\Delta u_{t+1}\right) \\
& =g^{o}-g-n+\Delta v_{t+1}-\Delta u_{t+1}
\end{aligned}
$$

The possibility of a long run impact from oil income to per capita output depends on the relative growth of oil income $\left(g^{o}\right)$ relative to the combined growth of labour and technology. In the case where $g^{o}<g+n, \chi_{t} \rightarrow 0$ as $t \rightarrow \infty$, the importance of oil income in the economy will tend towards zero in the limit and the standard growth model will become applicable. In this case oil income is neither a blessing nor a curse in the long run. This is as to be expected since with oil income rising but at a slower pace than the growth of real output, the share of oil income in aggregate output eventually tends towards zero. Therefore, a resource could be non-depletable but still have no long run impacts.

But if $g^{o} \geq g+n$, oil income continues to exert an independent impact on the process of capital accumulation even in the long run. Under this case $\chi_{t} \neq 0$ for all $t$, and scaling (9) by $\chi_{t}$ we obtain:

$$
\frac{\kappa_{t+1}}{\chi_{t+1}}=\left[(1-\delta) \frac{\kappa_{t}}{\chi_{t}}+s\left(\boldsymbol{\zeta}_{t}\right) \frac{f\left(\kappa_{t}\right)}{\chi_{t}}+\lambda\left(\boldsymbol{\zeta}_{t}\right)\right] \exp \left(-g-n-\Delta u_{t+1}\right) \exp \left(-\Delta \log \chi_{t+1}\right) .
$$


Denoting the scaled variables by $\sim$ such that $\widetilde{z}_{t}=z_{t} / \chi_{t}$, and using (11) we then have

$$
\widetilde{\kappa}_{t+1}=\left[(1-\delta) \widetilde{\kappa}_{t}+s\left(\boldsymbol{\zeta}_{t}\right) \widetilde{y}_{t}+\lambda\left(\boldsymbol{\zeta}_{t}\right)\right] \exp \left(-g^{o}-\Delta v_{t+1}\right) \text {. }
$$

where $\widetilde{y}_{t}=y_{t} / \chi_{t}=f\left(\kappa_{t}\right) / \chi_{t}$. In the case of a Cobb-Douglas production function, $f\left(\kappa_{t}\right)=\kappa_{t}^{\alpha}$, where $0<\alpha<1$ is the share of capital, we have

$$
\widetilde{\kappa}_{t+1}=\left[(1-\delta) \widetilde{\kappa}_{t}+s^{*}\left(\boldsymbol{\zeta}_{t}\right) \tilde{\kappa}_{t}^{\alpha}+\lambda\left(\boldsymbol{\zeta}_{t}\right)\right] \exp \left(-g^{o}-\Delta v_{t+1}\right) .
$$

where $s^{*}\left(\boldsymbol{\zeta}_{t}\right)=s\left(\boldsymbol{\zeta}_{t}\right) / \chi_{t}^{1-\alpha}=s\left(\boldsymbol{\zeta}_{t}\right) \chi_{0}^{-(1-\alpha)} e^{-(1-\alpha)\left(g^{o}-g-n\right) t-(1-\alpha)\left(v_{t}-u_{t}\right)}$. We need now to consider the cases where $g^{o}>g+n$, and $g^{o}=g+n$, separately. Under the former and since $1-\alpha>0$, and $s\left(\boldsymbol{\zeta}_{t}\right)$ is bounded in $\boldsymbol{\zeta}_{t}$, then $\lim _{t \rightarrow \infty} s^{*}\left(\boldsymbol{\zeta}_{t}\right)=0$, and for sufficiently large $t$ (13) behaves as

$$
\widetilde{\kappa}_{t+1}=\left[(1-\delta) \widetilde{\kappa}_{t}+\lambda\left(\boldsymbol{\zeta}_{t}\right)\right] \exp \left(-g^{o}-\Delta v_{t+1}\right),
$$

and $\kappa^{*}=\lim _{t \rightarrow \infty} \widetilde{\kappa}_{t}$ will exits so long as $E\left[(1-\delta) \exp \left(-g^{o}-\Delta v_{t+1}\right)\right]<1$. In the case where $v_{t}$ is normally distributed this condition can be written as $g^{o}>\sigma_{v}^{2}+\ln (1-\delta)$, and will be satisfied if growth of oil income is not too volatile. Based on historical data on real oil prices, $\sigma_{v}$ is around 20 per cent per annum, and taking $\delta=.05$ we would then need that $g^{o}>0.04-0.0513$ which is clearly met in practice.

In the knife-edge case where $g^{o}=g+n$, the limiting distribution of $\widetilde{\kappa}_{t}$ will be the function of both saving rates (savings out of domestic output and oil income) and will be ergodic only if certain regularity conditions on $s^{*}\left(\boldsymbol{\zeta}_{t}\right) / \widetilde{\kappa}_{t}$ and $\lambda\left(\boldsymbol{\zeta}_{t}\right) / \widetilde{\kappa}_{t}$ are met. Note that in the present case $s^{*}\left(\boldsymbol{\zeta}_{t}\right)=s\left(\boldsymbol{\zeta}_{t}\right) \chi_{0}^{-(1-\alpha)} e^{-(1-\alpha)\left(v_{t}-u_{t}\right)}$. Following Binder and Pesaran (1999), and assuming that $s^{*}\left(\boldsymbol{\zeta}_{t}\right) / \widetilde{\kappa}_{t}$ and $\lambda\left(\boldsymbol{\zeta}_{t}\right) / \widetilde{\kappa}_{t}$ are monotonic in $\boldsymbol{\zeta}_{t}$ and that certain regularity conditions hold, then it can be shown that as $t \rightarrow \infty, \widetilde{\kappa}_{t+1} \rightarrow \widetilde{\kappa}^{*}$, where $\widetilde{\kappa}^{*}$ is a time-invariant random variable with a non-degenerate probability distribution function.

To summarize, subject to familiar regularity conditions, we have

$$
\ln \kappa_{t+1} \sim I(0), \text { if } g^{o}<g+n,
$$

and

$$
\ln \widetilde{\kappa}_{t+1}=\ln \kappa_{t+1}-\ln \chi_{t+1} \sim I(0), \text { if } g^{o} \geq g+n,
$$

where $I(0)$ represents a stationary (integrated of order 0) variable. Also since under a CobbDouglas production function

$$
\ln \kappa_{t}=\alpha^{-1}\left[\ln \left(Y_{t} / L_{t}\right)-\ln \left(A_{t}\right)\right]
$$

then in terms of per capita output we have

$$
\ln \left(Y_{t} / L_{t}\right)-\ln \left(A_{t}\right) \sim I(0), \text { if } g^{o}<g+n,
$$

and

$$
\ln \left(Y_{t} / L_{t}\right)-(1-\alpha) \ln A_{t}-\alpha \ln \left(X_{t} / L_{t}\right) \sim I(0), \text { if } g^{o} \geq g+n .
$$

Therefore, the issue of whether oil income is likely to have a lasting impact on per capita output growth can be tested by a cointegration analysis involving log per capita output, log of real per capita oil income and an index of technological progress. In such an empirical 
analysis it is important that $A_{t}$ can be measured independently of oil income. With this in mind and following Garratt, Lee, Pesaran, and Shin (2003) we assume that domestic technology evolves from a diffusion and adaptation of foreign technology denoted by $A_{t}^{*}$. Specifically we assume that

$$
\ln \left(A_{t}\right)=a_{0}^{*}+\theta \ln \left(A_{t}^{*}\right)+\eta_{t},
$$

where $\theta$ measures the extent to which foreign technology is diffused and adapted successfully by the domestic economy in the long run, $\eta_{t}$ represents the transient differences between the levels of technological innovations, and $a_{0}^{*}$ is a fixed scaling factor. If $\theta<1$, this implies that the domestic technology is falling behind the rest of the world, while $\theta>1$ implies that the domestic technology is quickly catching up and outperforming foreign technological growth, while $\theta=1$ represents the case where domestic and foreign technology are assumed to grow at the same rate.

Denoting foreign capital stock in effective labour units by $\kappa_{t}^{*}$, and assuming a CobbDouglas production function we have (using the same specification as above but without oil income)

$$
\ln \left(Y_{t}^{*} / L_{t}^{*}\right)-\ln A_{t}^{*}=\alpha \ln \left(\kappa_{t}^{*}\right) \sim I(0),
$$

This result together with (18) now yields

$$
\ln \left(A_{t}\right)-\theta\left(Y_{t}^{*} / L_{t}^{*}\right) \sim I(0),
$$

which upon substitution in (16) and (17) gives the following long run relations in observables

$$
\ln \left(Y_{t} / L_{t}\right)-\theta \ln \left(Y_{t}^{*} / L_{t}^{*}\right) \sim I(0), \text { if } g^{o}<g+n,
$$

and

$$
\ln \left(Y_{t} / L_{t}\right)-\theta(1-\alpha) \ln \left(Y_{t}^{*} / L_{t}^{*}\right)-\alpha \ln \left(X_{t} / L_{t}\right) \sim I(0), \text { if } g^{o} \geq g+n .
$$

For the purpose of econometric modeling the long run interactions of real oil income with the other variables in the economy, it is convenient to decompose $\ln \left(X_{t} / L_{t}\right)$ as

$$
\ln \left(X_{t} / L_{t}\right)=\ln \left(E_{t} / P_{t}\right)+\ln \left(P_{t}^{o} X_{t}^{o} / L_{t}\right),
$$

where the first component, the real exchange rate, is treated as endogenous, and the second component, the per capita oil income in US dollars, can be viewed as exogenous for estimation purposes. Using this in (20) now yields

$$
\ln \left(Y_{t} / L_{t}\right)-\theta(1-\alpha) \ln \left(Y_{t}^{*} / L_{t}^{*}\right)-\alpha \ln \left(E_{t} / P_{t}\right)-\alpha \ln \left(P_{t}^{o} X_{t}^{o} / L_{t}\right) \sim I(0), \text { if } g^{o} \geq g+n .
$$

For empirical applications the analysis can be $\operatorname{simplified~if~} \ln \left(L_{t}\right)$ and $\ln \left(L_{t}^{*}\right)$ are trend stationary so that

$$
\ln \left(L_{t}\right)-n t \sim I(0) \text { and } \ln \left(L_{t}^{*}\right)-n^{*} t \sim I(0),
$$

where $n$ and $n^{*}$ are labour force growth rates of domestic and world economy. This allows for the possibility of both foreign and domestic demand shocks as long as they are temporary, or in other words $I(0)$. In this case the long run output equations become

$$
\ln \left(Y_{t}\right)-\theta \ln \left(Y_{t}^{*}\right)-\left(n-\theta n^{*}\right) t \sim I(0), \text { if } g^{o}<g+n,
$$


and

$$
\ln \left(Y_{t}\right)-\psi_{1} \ln \left(Y_{t}^{*}\right)-\psi_{2} \ln \left(E_{t} / P_{t}\right)-\psi_{3} \ln \left(P_{t}^{o} X_{t}^{o}\right)-\gamma t \sim I(0), \text { if } g^{o} \geq g+n
$$

where

$$
\psi_{1}=\theta\left(1-\psi_{2}\right), \psi_{2}=\psi_{3}=\alpha, \text { and } \gamma=(1-\alpha)\left(n-\theta n^{*}\right) .
$$

Equation (22) is sufficiently general and covers both cases where $g^{o}<g+n$ and $g^{o} \geq g+n$. Under the former $\psi_{1}=\theta, \psi_{2}=\psi_{3}=0$, whilst under the latter $\psi_{2}=\psi_{3} \neq 0$. The above formulation also allows us to test other hypothesis of interest concerning $\theta$ and $\gamma$. The value of $\theta$ provides information on the long run diffusion of technology to the oil exporting economy. The diffusion of technology is at par with the rest of the world if $\theta=1$, whilst a value of $\theta$ below unity suggests inefficiency that prevents the adoption of best practice techniques, possibly due to rent-seeking activities. When $\theta=1$ steady state per capita output growth in the oil exporting economy can only exceed that of the rest of the world if oil income per capita is rising faster than the steady state per capita output in the rest of the world. The steady state output growth in the oil exporting economy could be lower than the rest of the world per capita output growth if $\theta<1$. In case of the most resource abundant economies, where $g^{o}<g+n$, their steady state growth rates cannot exceed that of the rest of the world unless $\theta>1$. The empirical literature which is based on cross section regressions most likely captures short term deviations from the steady states and in view of the substantial heterogeneity that exists across countries can be quite misleading, particularly as far as identification of $\theta$ and inferences on management inefficiency of resource abundant economies are concerned.

In what follows we estimate $\theta$ and the other parameters of the long run output equation, (22), by embedding it within a vector error correcting model of the Iranian economy estimated on quarterly observations over the past 28 years since the 1979 Revolution. To this end we first re-write the output equation as

$$
y_{t}-\psi_{1} y_{t}^{*}=\psi_{2}\left(e_{t}-p_{t}\right)+\psi_{3} x o_{t}+c_{y}+\gamma_{y} t+\xi_{y, t}
$$

where $y_{t}=\ln \left(Y_{t}\right), y_{t}^{*}=\ln \left(Y_{t}^{*}\right), e_{t}=\ln \left(E_{t}\right), p_{t}=\ln \left(P_{t}\right), x o_{t}=\ln \left(X_{t}^{o} P_{t}^{o}\right), c_{y}$ is a fixed constant, and $\xi_{y, t}$ is a mean zero stationary process, which represents the error correction term of the long run output equation. In addition to the output equation we also consider the real money demand equation $(\mathrm{MD})$,

$$
m_{t}-p_{t}=\phi_{1} y_{t}+\phi_{2}\left(p_{t}-p_{t-1}\right)+c_{m p}+\gamma_{m p} t++\xi_{m p, t},
$$

where $m p_{t}=m_{t}-p_{t}$ is real money balances, and $\xi_{m p, t}$ is the stationary error correcting term for the MD equation.

A number of other long run relations considered in the literature, namely the purchasing power parity (PPP), the uncovered interest parity and the Fisher equation could also be included, see Garratt, Lee, Pesaran, and Shin (2006) for further details. But we have not been able to include these in our analysis as available data on interest rates are administratively determined, changed only at infrequent intervals, and as such do not reflect the market conditions. The money supply also comes to play an important role in the Iranian economy, since the capital markets are not developed in Iran. For the same reason we have used the 
inflation rate, $\pi_{t}=p_{t}-p_{t-1}$ rather than the interest rate in the MD equation specified above. Inflation rate could be a good proxy for short term interest rate assuming that the Fisher equation holds, at least in the long run. The analysis of PPP in Iran is also complicated by a prolonged period of black market in foreign exchange and the existence of multiple exchange rates, see Pesaran (1992). Also, to include a PPP relationship in the model, we need to introduce an effective exchange rate in addition to the US dollar rate, $E_{t}$. However, as a result of US sanctions only a very small fraction of Iran's trade is conducted with the US, and the use of US price level as a proxy for foreign prices will not be appropriate. Further work is clearly need before a PPP relation can be added to the model in a satisfactory manner.

Our modelling strategy closely follows Garratt et al. (2003, 2006) and estimate a cointegrating VARX ${ }^{*}$ model with $\mathbf{x}_{t}=\left(y_{t}, m p_{t}, \pi_{t}, e_{t}-p_{t}\right)^{\prime}$ as the endogenous variables, and $\mathbf{x}_{t}^{*}=\left(y_{t}^{*}, x o_{t}\right)^{\prime}$ as the exogenous variables. But before giving the details of the econometric model, we first discuss the data and the main economic trends of the Iranian economy over the period 1979Q1-2006Q4. A review of the macroeconometric modelling literature for the Iranian economy is also provided to better place our contribution within the existing literature, but since it is not central to our main arguments it is relegated to Appendix A.

\section{Macroeconomic Trends in Iran Since the 1979 Rev- olution}

Iran's economy has gone through two major phases since the Islamic Revolution of 1979. The first phase was the aftermath of the Revolution and eight years of war with Iraq. Those years were characterized by mobilization of resources to deal with internal and external conflicts, massive extension of government controls over firms and markets, and efforts to define the institutions of the new political system, the Islamic Republic. The second phase started in 1989 with post-war reconstruction and a series of economic and institutional reforms. After a few years of market-oriented reforms, the government proceeded to liberalize the foreign exchange market and open up the capital account in 1993. But, the process was not managed well and the country quickly accumulated a huge stock of short-term external debt, followed by a major balance of payments crisis in 1993-1994, see Pesaran (2000) and Esfahani and Pesaran (2009). The debt crisis put the reform program on hold and even reversed it in many areas, especially in the credit and foreign exchange markets. After the mid-1990s, a process of gradual change began in which the government tried to deal with the economy's problems in a more cautious manner.

The performance of real GDP since early 1979 is depicted in Figure 2. Before the Revolution of February 1979, the Iranian economy was already on a downward trend. But, it went into a tailspin that lowered the real GDP by almost a quarter of its 1979Q1 value in the two subsequent years. Part of the problem was the redistributive and political conflicts that undermined the production and investment incentives. The government quickly took over all large firms and all banks and financial companies, restricted trade and capital movements, and expropriated the properties of those believed to be associated with the Shah's regime. Property rights came into question more generally and the economy began to witness a major exodus of skilled labor. The costly war with Iraq during 1980-1988 also 


\title{
Figure 2: Domestic (y) and foreign output (ys)
}

\author{
Log level
}

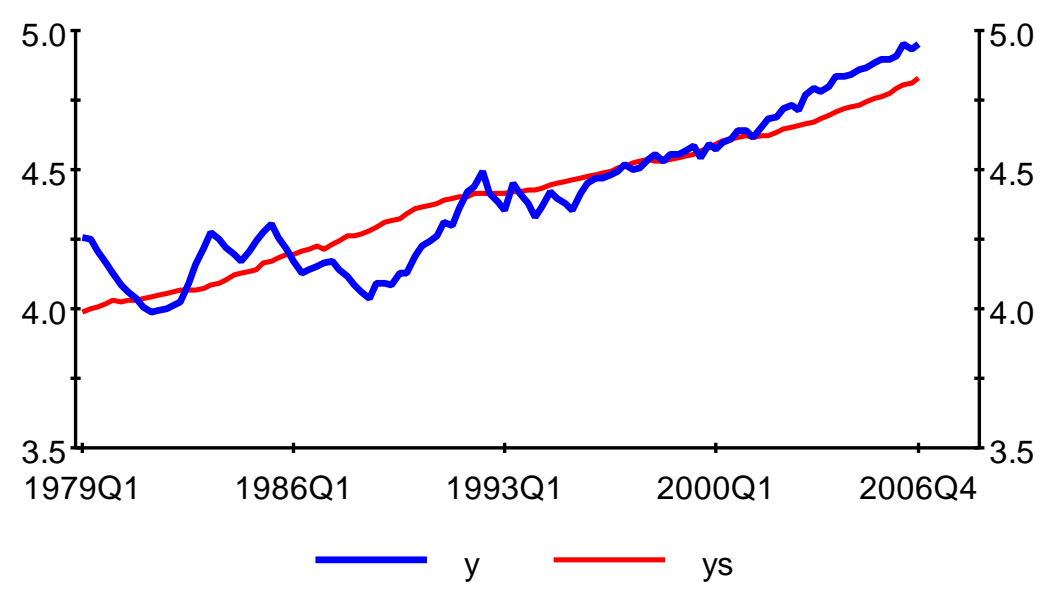

caused destruction of property and infrastructure and increasingly drained resources away from productive investment (Figure 2).

A sharp drop in oil revenues between 1980 and 1982 must have also contributed to the decline in real GDP, see Figure 3. Indeed, as oil revenues rose in 1982-1984 and then dropped again during 1984-1986, the real GDP followed suit. Similar co-movements, especially long term ones, can be seen after the end of the war in 1988 as well (Figure 3). The rise of oil revenues during 1989-1991 helped the Iranian economy's quick recovery from the war and the decline of those revenues in 1993 triggered the balance of payments crisis that pushed Iran's real GDP below its trend until the late 1990s. On the other hand, the recovery of oil prices in 2000 and especially after 2002 ushered in a period of relatively high growth that, so far, has lasted several years. As described in Section 2.1 we model this association between oil revenues and real GDP in the long run and confirm its existence and significance in our econometric exercise in Section 5.2.

Oil revenues have also had an important impact on the real exchange rate. The decline in oil revenues in the mid-1990s increased the purchasing power of the dollar in terms of domestic output, a process that has been reversed since the late 1990, see Figure 4. Before the mid-1990s, the connection between the two variables was different because at that time the government controlled both foreign trade and the foreign exchange market much more tightly and tried to keep the real exchange rate of the dollar low by suppressing the demand for imports. These controls became tighter when oil revenues declined, inducing a positive correlation between foreign earnings and the real price of the dollar (Figure 4). Such interventions must have had adverse effects on the real GDP for a number of reasons. Besides causing inefficient allocation and discouraging exports, lower real value of the dollar meant that oil revenues could buy less domestic goods and resulted slower capital formation. Our econometric results are consistent with this claim. 
Figure 3: Oil export revenues (xo) and deviation of domestic from foreign output $(\mathrm{y}-\mathrm{ys})$

Log level

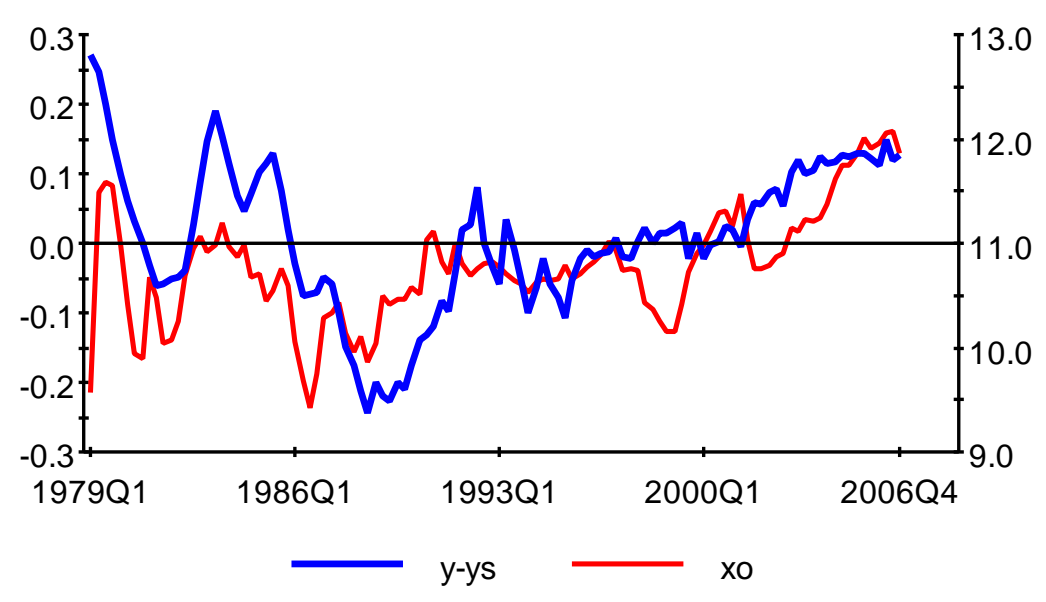

Figure 4: Real exchange rate (ep) and deviation of domestic from foreign output $(\mathrm{y}-\mathrm{ys})$

Log level

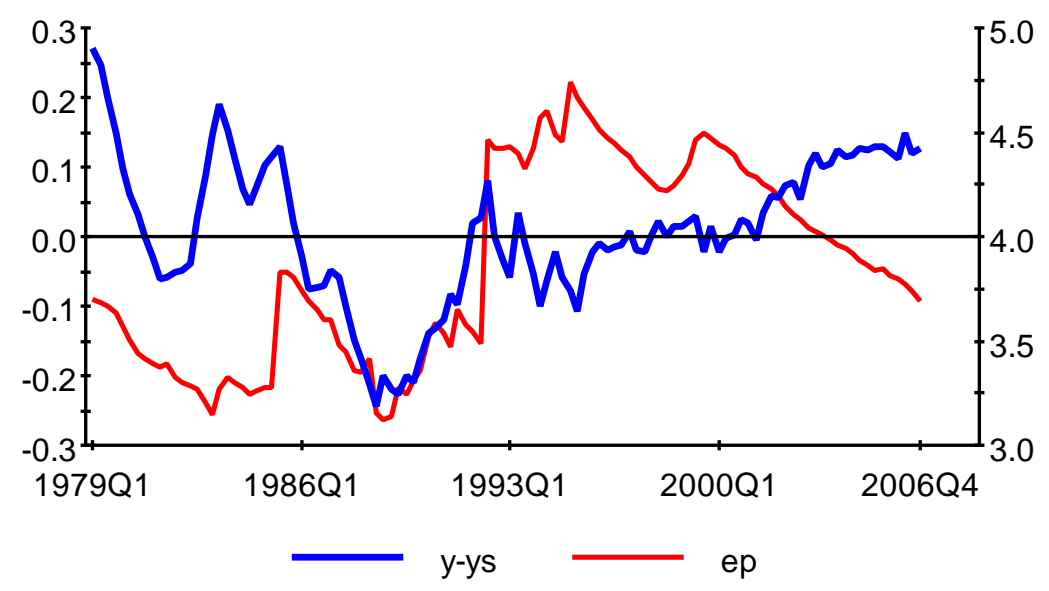




\title{
Figure 5: Inflation (dp) and deviation of domestic from foreign output (y-ys)
}

\author{
Log level
}

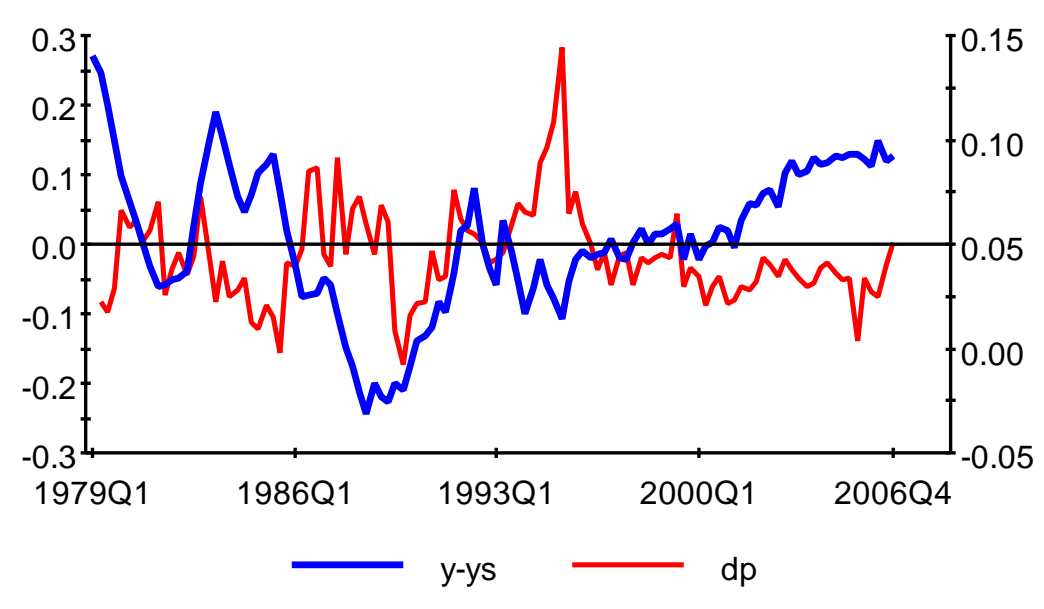

Tightening of market controls in response to shocks was also a means of controlling inflation. However, those measures could not work beyond the short or medium term and often resulted in high inflation in the longer run. Institutional weaknesses in managing money supply, aggregate demand, and the operation of the markets in general also often manifested themselves in heightened inflation. As Figure 5 shows, the rate of inflation rose sharply in the early 1980s when the economy was grappling with internal political instability, external conflict, and declining oil revenues. The government managed to use money expansion and rationing of goods to keep up the real balances in those years (Figure 6). In 1984 and 1985, the recovery of oil revenues helped lower inflation and raise output. But, the drop in oil prices in 1986 and the continuation of the war led to a sharp rise in inflation and the collapse of aggregate output and real balances until 1989 (Figure 6).

End of war with Iraq and the start of reconstruction briefly lowered inflation and boosted real balances (Figures 5 and 6). But, deregulation of many markets and a large depreciation of the rial (see Figure 4) allowed prices to jump up in 1990. This was followed by a rapid expansion of credit and fiscal spending, which fueled inflation during the early 1990s. Increased imports and output growth were gradually lowering inflation when the balance of payments crisis of 1993-1994 broke out and led to shortage of imports and a significant depreciation of the rial. At the same time, the policy-makers decided to compensate those who owed foreign debt for their losses due to the depreciation. These developments jointly sent inflation soaring in 1995 and brought down real balances sharply (Figures 5 and 6). In the following years, the government managed to bring down the rate of inflation to more moderate rates and stabilize the real balances, see Amuzegar (1997). Once the economy proved stable in the early 2000s, real balances took off and soon regained its position relative to the real GDP (Figure 6). However, in recent years, as oil revenues have increased, the government's monetary and fiscal policies have become quite expansionary and have raised 


\section{Figure 6: Real money balances (mp) and domestic output (y)}

\section{Log level}

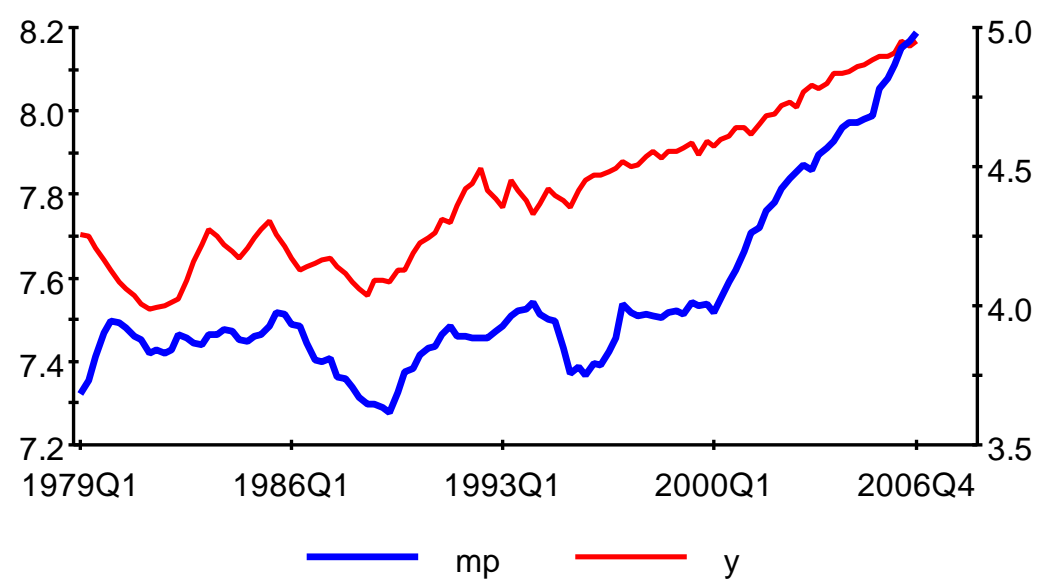

inflation to higher levels again.

\section{A VARX* Error Correcting Model for Iran}

In this section we begin by showing how the two long run relations given by (24) and (25) can be embodied in a vector error correcting model. We first note that the two long run relations can be written compactly as deviations from equilibrium:

$$
\boldsymbol{\xi}_{t}=\boldsymbol{\beta}^{\prime} \mathbf{z}_{t}-\mathbf{c}-\gamma t
$$

where

$$
\begin{aligned}
\mathbf{z}_{t} & =\left(\mathbf{x}_{t}^{\prime}, \mathbf{x}_{t}^{* \prime}\right)^{\prime}=\left(y_{t}, m p_{t}, \pi_{t}, e p_{t}, y_{t}^{*}, x o_{t}\right)^{\prime} \\
\mathbf{c} & =\left(c_{y}, c_{m p}\right)^{\prime}, \boldsymbol{\gamma}=\left(\gamma_{y}, \gamma_{m p}\right)^{\prime}, \boldsymbol{\xi}_{t}=\left(\xi_{y t}, \xi_{m p, t}\right)^{\prime}
\end{aligned}
$$

and

$$
\boldsymbol{\beta}^{\prime}=\left(\begin{array}{cccccc}
-1 & 0 & 0 & \psi_{2} & \psi_{1} & \psi_{3} \\
\phi_{1} & -1 & \phi_{2} & 0 & 0 & 0
\end{array}\right)
$$

The long run theory for oil exporting countries, as derived in Section 2.1, require two further restrictions on the output equation (24) for Iran, namely $\psi_{2}=\psi_{3}=\alpha$ and $\psi_{1}=$ $\theta(1-\alpha)$, where we are interested in seeing whether in fact the coefficients of the real exchange rate and total oil revenues from oil exports are the same and equal to the share of capital in output $(\alpha)$ and whether technological progress in Iran is on par with that of the rest of the world, in other words whether $\theta=1$, and as a result the coefficient of the foreign real output is equal to $(1-\alpha)$. 
The $\operatorname{VARX}^{*}\left(s, s^{*}\right)$ model that embodies $\boldsymbol{\xi}_{t}$ is constructed from a suitably restricted version of the VAR in $\mathbf{z}_{t}$. In the present application $\mathbf{z}_{t}=\left(\mathbf{x}_{t}^{\prime}, \mathbf{x}_{t}^{* \prime}\right)^{\prime}$ is partitioned into the $4 \times 1$ vector of endogenous variables, $\mathbf{x}_{t}=\left(y_{t}, m p_{t}, \pi_{t}, e p_{t}\right)$, and the $2 \times 1$ vector of the weakly exogenous variables, $\mathbf{x}_{t}^{*}=\left(y_{t}^{*}, x o_{t}\right)^{\prime}$. Also as shown in Appendix $\mathrm{C}$, the hypothesis that all the six variables are $I(1)$ cannot be rejected. Moreover, it is easily established that the two exogenous variables are not cointegrated. Under these conditions, following Pesaran, Shin, and Smith (2000), the VAR in $\mathbf{z}_{t}$ can be decomposed into the conditional model for the endogenous variables:

$$
\Delta \mathbf{x}_{t}=-\boldsymbol{\Pi}_{x} \mathbf{z}_{t-1}+\sum_{i=1}^{s-1} \boldsymbol{\Psi}_{i} \Delta \mathbf{x}_{t-i}+\boldsymbol{\Lambda}_{0} \Delta \mathbf{x}_{t}^{*}+\sum_{i=1}^{s^{*}-1} \boldsymbol{\Lambda}_{i} \Delta \mathbf{x}_{t-i}^{*}+\mathbf{a}_{0}+\mathbf{a}_{1} t+\boldsymbol{v}_{t}
$$

and the marginal model for the exogenous variables:

$$
\Delta \mathbf{x}_{t}^{*}=\sum_{i=1}^{s-1} \boldsymbol{\Gamma}_{i}^{*} \Delta \mathbf{z}_{t-i}+\mathbf{b}_{0}+\mathbf{u}_{x^{*} t}
$$

If the model includes an unrestricted linear trend, in general there will be quadratic trends in the level of the variables when the model contains unit roots. To avoid this, the trend coefficients are restricted such that $\mathbf{a}_{1}=\boldsymbol{\Pi}_{x} \boldsymbol{\delta}$, where $\boldsymbol{\delta}$ is an $6 \times 1$ vector of free coefficients, see Pesaran, Shin, and Smith (2000) and Section 6.3 in Garratt, Lee, Pesaran, and Shin (2006). The nature of the restrictions on $\mathbf{a}_{1}$ depends on the rank of $\boldsymbol{\Pi}_{x}$. In the case where $\boldsymbol{\Pi}_{x}$ is full rank, $\mathbf{a}_{1}$ is unrestricted, whilst it is restricted to be equal to $\mathbf{0}$ when the rank of $\boldsymbol{\Pi}_{x}$ is zero. Under the restricted trend coefficients the conditional model can be written as

$$
\Delta \mathbf{x}_{t}=-\boldsymbol{\Pi}_{x}\left[\mathbf{z}_{t-1}-\boldsymbol{\delta}(t-1)\right]+\sum_{i=1}^{s-1} \boldsymbol{\Psi}_{i} \Delta \mathbf{x}_{t-i}+\boldsymbol{\Lambda}_{0} \Delta \mathbf{x}_{t}^{*}+\sum_{i=1}^{s^{*}-1} \boldsymbol{\Lambda}_{i} \Delta \mathbf{x}_{t-i}^{*}+\tilde{\mathbf{a}}_{0}+\boldsymbol{v}_{t}
$$

where $\tilde{\mathbf{a}}_{0}=\mathbf{a}_{0}+\boldsymbol{\Pi}_{x} \boldsymbol{\delta}$. We refer to this specification as the vector error correcting model with weakly exogenous $I(1)$ variables, or $\operatorname{VECX}^{*}\left(s, s^{*}\right)$ for short. Note that $\tilde{\mathbf{a}}_{0}$ remains unrestricted since $\mathbf{a}_{0}$ is not restricted. While for consistent and efficient estimation (and inference) we only require the conditional model as specified in (28), for impulse response analysis and forecasting we need the full system vector error correction model which also includes the marginal model; as such we need to specify the process driving the weakly exogenous variables, $\Delta \mathbf{x}_{t}^{*}$.

The long run theory imposes a number of restrictions on $\boldsymbol{\Pi}_{x}$ and $\boldsymbol{\delta}$. First, for the conditional model to embody the equilibrium errors defined by, (26), we must have $\boldsymbol{\Pi}_{x}=$ $\boldsymbol{\alpha}_{x} \boldsymbol{\beta}^{\prime}$, which in turn implies that $\operatorname{rank}\left(\boldsymbol{\Pi}_{x}\right)=2$. Furthermore, the restrictions on the trend coefficients are given by

$$
\Pi_{x} \boldsymbol{\delta}=\boldsymbol{\alpha}_{\mathbf{x}} \boldsymbol{\beta}^{\prime} \boldsymbol{\delta}=\boldsymbol{\gamma}
$$

Since under cointegration $\boldsymbol{\alpha}_{x} \neq \mathbf{0}$, it then follows that a trend will be absent from the long run relations if one of the two elements of $\boldsymbol{\beta}^{\prime} \boldsymbol{\delta}$ is equal to zero. These restrictions are known as co-trending restrictions, meaning that the linear trends in the various variables of the long run relations gets cancelled out. This hypothesis is important in the analysis of output 
convergence between domestic and the foreign variables, since without such a co-trending restriction the two output series will diverge even if they are shown to be co-integrated.

The theory also imposes a number of long run over-identifying restrictions on the elements of $\boldsymbol{\beta}$. The total number of over-identifying restrictions is given by $12-4=8$, and there are 4 structural parameters to be estimated, $\alpha, \theta, \phi_{1}$ and $\phi_{2}$. This leaves us with 4 over-identifying restrictions to test.

\section{$5 \quad$ Long Run Estimates and Tests}

\subsection{Order Selection and Deterministic Components}

We propose to use the $\operatorname{VECX}^{*}\left(s, s^{*}\right)$ model defined by (30) to test the various long run theory restrictions set out above. First we need to determine the lag orders $s$ and $s^{*}$ in the $\operatorname{VARX}^{*}\left(s, s^{*}\right)$ model. ${ }^{4}$ For this purpose we use the Akaike Information Criterion (AIC) and the Schwarz Bayesian Criterion (SBC) applied to the underlying unrestricted VARX* model. The results are summarized in Table 1 . SBC selects the lag orders $\hat{s}=\hat{s}^{*}=1$, whilst, as to be expected, AIC selects a higher order lag for the endogenous variables, namely $\hat{s}=2$ and $\hat{s}^{*}=1$. We follow AIC and base our analysis on the $\operatorname{VARX}^{*}(2,1)$, since under-estimating the lag orders is generally more serious than overestimating them.

Table 1: Lag order selection criteria

\begin{tabular}{llll}
\hline \multicolumn{2}{l}{ Lag length } & AIC & SBC \\
\hline$s=1$ & $s^{*}=1$ & 1455.32 & 1327.48 \\
$s=1$ & $s^{*}=2$ & 1445.35 & 1277.14 \\
$s=2$ & $s^{*}=1$ & 1459.09 & 1297.61 \\
$s=2$ & $s^{*}=2$ & 1451.63 & 1249.78 \\
\hline
\end{tabular}

Notes: AIC refers to the Akaike Information Criterion and SBC refers to the Schwarz Bayesian Criterion.

As to the deterministic variables included in our model we make use of both a constant and a linear trend. As a trend may or may not be found in the long run relations we also test for co-trending restrictions given by $\boldsymbol{\beta}^{\prime} \boldsymbol{\delta}=\mathbf{0}$. We also experimented with including a war and revolution (WR) dummy amongst the determinstics. The WR dummy takes the value of 1 between 1979 quarter 1 and 1988 quarter 2 and zeros outside this period, and is intended to capture the joint effects of the 1979 Islamic Revolution and the war with Iraq which lasted from September 1980 until August 1988. The WR dummy could also pick up the effects of economic liberalisation that took place after the ending of the Iran-Iraq war. But as we shall argue in Section 5.2.3 below, once $x o_{t}$, the oil exports variable, is included in the model the WR dummy ceases to be statistically significant.

\footnotetext{
${ }^{4}$ All estimations and test results are obtained using Microfit 5.0. For further technical details see Pesaran and Pesaran (2009), Section 22.10.
} 


\subsection{Estimation and Testing of the Long Run Relations}

Having established the order of VARX* to be $(2,1)$ we need to determine the number of cointegrating relations given by $r=\operatorname{rank}\left(\boldsymbol{\Pi}_{x}\right)$, where $\boldsymbol{\Pi}_{x}$ is defined by (30). Cointegration tests with null hypothesis of no cointegration, one cointegrating relation, and so on are carried out using Johansen's maximum eigenvalue and trace statistics as developed in Pesaran, Shin, and Smith (2000) for models with weakly exogenous regressors. The test results are reported in Table 2. Both the maximal eigenvalue and the trace statistics suggest the presence of two cointegrating relations at the 5 per cent level, which is the same as that suggested by economic theory, thus we set $r=2$.

Table 2: Cointegration rank test statistics for the $\operatorname{VARX}^{*}(2,1)$ model with endogenous variables $(\mathrm{y}, \mathrm{mp}, \mathrm{dp}, \mathrm{ep})$ and the weakly exogenous variables $\left(\mathrm{y}^{*}, \mathrm{xo}\right)$

\begin{tabular}{|c|c|c|c|c|}
\hline$H_{0}$ & $H_{1}$ & Test statistic & 95\% Critical Values & 90\% Critical Values \\
\hline \multicolumn{5}{|c|}{ (a) Maximal eigenvalue statistic } \\
\hline$r=0$ & $r=1$ & 55.84 & 41.93 & 38.29 \\
\hline$r \leq 1$ & $r=2$ & 40.31 & 33.79 & 31.23 \\
\hline$r \leq 2$ & $r=3$ & 24.66 & 26.26 & 23.93 \\
\hline$r \leq 3$ & $r=4$ & 6.30 & 17.73 & 16.08 \\
\hline \multicolumn{5}{|c|}{ (b) Trace statistic } \\
\hline$r=0$ & $r=1$ & 127.11 & 90.44 & 84.24 \\
\hline$r \leq 1$ & $r=2$ & 71.27 & 60.13 & 56.47 \\
\hline$r \leq 2$ & $r=3$ & 30.97 & 36.97 & 34.02 \\
\hline$r \leq 3$ & $r=4$ & 6.30 & 17.73 & 16.08 \\
\hline
\end{tabular}

Notes: The underlying VARX* model is of order $(2,1)$ and contains unrestricted intercept and restricted trend coefficients. $y_{t}^{*}$ and $x o_{t}$ are treated as weakly exogenous, non-cointegrated $I(1)$ variables. The test statistics refer to Johansen's log-likelihood-based maximum eigenvalue and trace statistics and are computed using 109 observations from 1979Q4 to 2006Q4.

In order to exactly identify the long run relations, we must impose 4 restrictions, 2 restrictions on each of the 2 cointegration relations. The choice of the exactly identifying restrictions is econometrically innocuous and is best guided by economic theory. We proceed by taking the first cointegrating relation to be the output equation, defined by equation (24) and normalised on $y_{t}$, and the second one the money demand equation, defined by (25) and normalised on $m p_{t}=m_{t}-p_{t}$. Accordingly, we start with the following two exactly identified cointegrating vectors

$$
\boldsymbol{\beta}_{E X}^{\prime}=\left(\begin{array}{cccccc}
-1 & 0 & \beta_{13} & \beta_{14} & \beta_{15} & \beta_{16} \\
\beta_{21} & -1 & \beta_{23} & \beta_{24} & 0 & \beta_{26}
\end{array}\right),
$$

where the rows of $\boldsymbol{\beta}_{E X}^{\prime}$ correspond to $\mathbf{z}_{t}=\left(y_{t}, m p_{t}, \pi_{t}, e p_{t}, y_{t}^{*}, x o_{t}\right)^{\prime}$. Using this exactly identified specification we then test the co-trending restrictions, $\boldsymbol{\beta}^{\prime} \boldsymbol{\delta}=\boldsymbol{\gamma}=\left(\gamma_{y}, \gamma_{m p}\right)^{\prime}=\mathbf{0}$. The log-likelihood ratio (LR) statistic for jointly testing the two co-trending restrictions takes the value 10.15, and is asymptotically distributed as a chi-squared variate with two degrees of freedom. Therefore, based on the asymptotic distribution the co-trending restrictions are rejected. But we are working with a relatively large dimensional VARX* model using a moderate number of time series observations. In such situations it is known that the 
LR tests could over-reject in small samples (see, for example, Gredenhoff and Jacobson (2001) as well as Gonzalo (1994), Haug (1996) and Abadir, Hadri, and Tzavalis (1999)). To deal with the small sample problem we computed bootstrapped critical values based on 1,000 replications of the LR statistic. Using the observed initial values of each variable, the estimated model, and a set of random innovations, an artificial data set is generated for each of the 1,000 replications under the assumption that the estimated version of the model is the true data-generating process. For each of the replicated data sets, we first estimate our $\mathrm{VECX}^{*}$ model subject to the exact identifying restrictions in (31) and then subject to the two co-trending restrictions. Finally, the empirical distribution of the LR test statistic is derived using the 1,000 replications. Having applied this technique, the bootstrapped critical value for the joint test of the two co-trending restrictions is 10.20 at the 5 percent level, and 15.22 at the 1 percent level, as compared to the LR statistic of 10.15. Hence, based on the bootstrapped critical values the co-trending restrictions cannot be rejected at the conventional levels of significance, although the outcome of the test at the 5 percent level is rather marginal and is subject to the random variation of the bootstrapped critical values. We shall, therefore, impose the co-trending restrictions whilst considering the other theory restrictions, and return to them to see if they continue to be supported by the data once the other restrictions are imposed.

\subsubsection{Testing Long Run Theory Restrictions}

We first consider the theory restrictions on the output equation whilst maintaining the exact identifying restrictions on the second long run relation. Initially we impose the restriction that the coefficients of $e p_{t}$ and $x o_{t}$ are the same, namely that in (31) $\beta_{14}=\beta_{16}=\alpha$. We obtain the estimates

$$
\hat{\psi}_{1}=\underset{(0.2183)}{0.6931}, \hat{\psi}_{2}=\hat{\psi}_{3}=\hat{\alpha}=\underset{(0.1100)}{0.3140}
$$

with the LR statistic of 10.52 for testing the three restrictions. The figures in brackets are asymptotic standard errors. The additional restriction has only marginally increased the LR statistic and is clearly not rejected. In fact the bootstrapped critical values for the test is now 11.91 at the 5 percent level and 17.12 at the 1 percent level. The implicit estimate of $\theta$ given by $0.6931 /(1-0.3140)=1.01$ is very close to unity and the null hypothesis that $\theta=1$ cannot be rejected, thus implying that the technological growth in Iran is on par with that off the rest of the world. Under $\theta=1$ we have $\beta_{15}+\beta_{14}=1$, and imposing this additional restriction the LR statistic increases only marginally from 10.5181 to 10.5198 . However, the estimate of $\alpha$, representing the share of capital, is relatively low, although not far from what is being considered in the literature for Iran, for instance see Mojaver (2009) in which he considers a range of 0.33 to 0.45 for $\alpha$. In addition, the coefficient of $\pi_{t}$ in the long run output equation is $\hat{\beta}_{13}=-14.72$ (5.91), which is statistically significant, implying that inflation has a negative effect on real output which is not supported by the long run theory. This negative effect suggests inefficiencies in both the institutions and economic policies in Iran and shows the importance of controlling inflation for growth promotion in Iran.

Consider now the second long run equation. The theory restrictions in terms of the elements of $\boldsymbol{\beta}$ in (31) are

$$
\beta_{24}=0 \text {, and } \beta_{26}=0 \text {. }
$$


Imposing these additional restrictions on $\boldsymbol{\beta}$ yields

$$
\begin{aligned}
\theta & =1, \hat{\alpha}=\underset{(0.0465)}{0.2333}, \hat{\beta}_{13}=\underset{(4.01)}{-13.06}, \\
\hat{\phi}_{1} & =\underset{(0.1231)}{0.8277}, \hat{\phi}_{2}=\underset{(6.09)}{-14.53} .
\end{aligned}
$$

The long run income elasticity of money demand is close to unity and the null hypothesis that it is equal to 1 cannot be rejected. The effect of inflation on real money balances is also negative and statistically significant. This is in line with our earlier discussion that inflation in the money demand equation acts as a proxy for the interest rate. In fact it would be a perfect proxy if it can be assumed that the Fisher parity holds in Iran. Imposing $\phi_{1}=1$ and re-estimating subject to all the seven over-identifying restrictions we obtain

$$
\begin{aligned}
\theta & =1, \hat{\alpha}=\underset{(0.0489)}{0.2647}, \hat{\beta}_{13}=-\underset{(4.37)}{-13.84}, \\
\phi_{1} & =1, \hat{\phi}_{2}=\underset{(6.79)}{-16.37}
\end{aligned}
$$

The LR statistic for testing all the 7 restrictions jointly is 23.34 which is to be compared to the bootstrapped critical values of 21.59 and 30.99 at the 5 and 1 percent significance levels, respectively. Therefore, the restrictions are rejected at 5 percent level, but not at the 1 percent level. The test outcome is inconclusive and further investigation seems in order. We considered relaxing some of the restrictions in the real money demand equation and found that the primary source of the rejection of the restrictions is the zero restriction imposed on the coefficient of the real exchange rate variable. Once this restriction is relaxed the following estimates are obtained

$$
\begin{gathered}
\theta=1, \hat{\alpha}=\underset{(0.0600)}{0.2467}, \hat{\beta}_{13}=\underset{(3.36)}{-12.06}, \\
\phi_{1}=1, \hat{\phi}_{2}=\underset{(2.99)}{-1.91}, \hat{\beta}_{24}=\underset{(0.0496)}{-0.2380} .
\end{gathered}
$$

There are now six over-identifying restrictions on the long run relations, and the LR statistic for testing these restrictions is 13.37 as compared to the bootstrapped critical values of 16.29 and 19.34 at the 10 and 5 percent significance levels, respectively. Clearly, the restrictions are not rejected even at the 10 percent significance level. This is reassuring particularly as far as the long run estimates of the output equation is concerned, since whether $\beta_{24}$ is restricted or not seems to have little effects on the estimates of the output equation, which is the focus of the present investigation. However, relaxing $\beta_{24}=0$ does significantly affect the inflation elasticity of the money demand which is reduced from -16.37 to -1.91 and is no longer statistically significant.

We are presented with a clear choice. Should we maintain the theory restrictions which are rejected at the 5 percent level, although not at the 1 percent level, or should we opt for the new specification of the real money demand equation that includes the $e_{t}-p_{t}$ variable which is difficult to justify in an economically meaningful sense. Given that we are primarily interested in the long run effects of oil exports for real output, and the choice of the real money demand equation does not seem to play a central role for that issue, in the rest of 
the paper we shall maintain the theory consistent money demand equation since it is easier to interpret. Also, since the theory restrictions are not rejected at the 1 percent level, our adherence to a theory consistent real money demand equation is not without some empirical foundations.

Furthermore, the theory consistent specifications are robust to alternative measurements of foreign output and the exchange rate. For instance, estimating the VECX* model with foreign output computed using fixed weights based on the average of three consecutive years (2001-2003), yield similar outcomes

$$
\begin{aligned}
\theta & =1, \hat{\alpha}=\underset{(0.0432)}{0.2311}, \hat{\beta}_{13}=-\underset{(5.08)}{-17.13} \\
\phi_{1} & =1, \hat{\phi}_{2}=\underset{(6.30)}{-16.06}
\end{aligned}
$$

to when we use foreign output based on time-varying weights $\left(y_{t}^{*}\right)$, with the 7 over-identifying restriction now not being rejected at the 5 percent significance level.

\subsubsection{Free and Official Exchange Rates}

As noted earlier, a similar issue of measurement also arises with respect to the exchange rate. Since the 1979 Revolution the Iranian rial has depreciated significantly against the US dollar under a variety of exchange rate regimes from a fixed rate to multiple rates and back to a unified pegged managed rate. It has depreciated from 70 rials per US dollar in 1979 to 9170 rials in 2006, or around 131 fold increase, see Pesaran (1984) and Pesaran (2000). Figure 7 shows (in logs) the free rate (or black market in certain periods), $e_{t}$, and the official exchange rate , $e_{O F, t}$, over the period 1979Q1-2006Q4. The two rates are at par at the start of the Revolution but depart soon thereafter. They are, however, brought in line by two major jumps the last of which is associated with the successful unification of the exchange rates during Khatami's Presidency in 2002.

To investigate the robustness of our results to the choice of the exchange rate we employ a geometrically weighted average of the free and the official rates, $e_{\omega, t}=\omega e_{t}+(1-\omega) e_{O F, t}$. The weights $\omega:(1-\omega)$ are intended to reflect the proportion of imports by public and private agencies that are traded at the two exchange rates, on average. There is little hard evidence on $\omega$, although due to the gradual attempts at currency unification, it is reasonable to expect $\omega$ to have risen over time. Initially we set $\omega=0.75$, but smaller values of $\omega=0.70$ and 0.60 resulted in very similar estimates and test outcomes. Using $e_{\omega, t}$ with $\omega=0.75$ we could not reject the 7 over-identifying restrictions even at the 10 percent level, since the LR statistic is 18.65 as compared to the bootstrapped critical values of 19.10 and 22.67 at the 10 and 5 percent significance levels, respectively. For $\omega=0.75$ we obtained the following estimates:

$$
\begin{aligned}
\theta & =1, \hat{\alpha}=\underset{(0 . .0308)}{0.1964}, \hat{\beta}_{13}=\underset{(2.55)}{-8.97}, \\
\phi_{1} & =1, \hat{\phi}_{2}=\underset{(6.84)}{-16.01}
\end{aligned}
$$

which yield a smaller capital share of 0.1964 as compared to 0.2647 , with the coefficient of inflation in the output equation still negative and statistically significant. However, the 


\section{Figure 7: Free and official exchange rates}

\section{Log level}

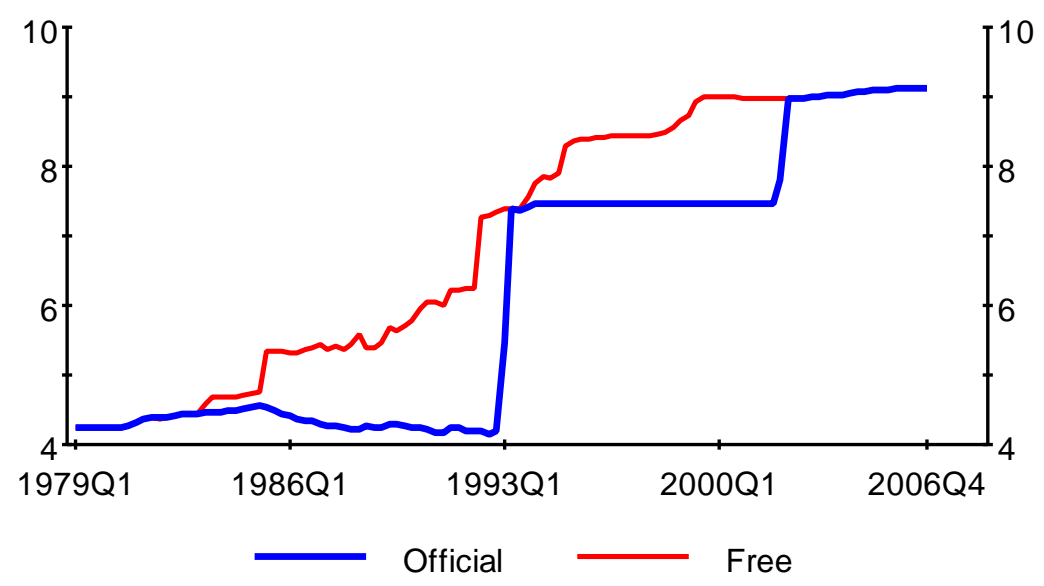

inflation elasticity of money demand, -16.01, is roughly the same as in the case when we use the floating exchange rate, $e_{t}$. Given that we do not know what these weights should be, for now we will proceed by only reporting the results when using the free exchange rate in our model, but we will return to this issue when looking at the short run dynamics. ${ }^{5}$

\subsubsection{Including a War and Revolution Dummy}

To see if the model captures the effects of the 1979 Islamic Revolution as well as the war with Iraq, which lasted from September 1980 until August 1988 and the economic liberalisation that followed after the war, we introduce a war and revolution dummy. This dummy takes the value of unity over the period 1979Q1 to 1988Q2, and zero otherwise. As before both the maximal eigenvalue and the trace statistics indicate the presence of two cointegrating relations at the 5 percent level. ${ }^{6}$ Setting $r=2$ and imposing the same over-identifying restrictions as in the above Sub-sections, namely:

$$
\begin{aligned}
\boldsymbol{\beta}^{\prime} \boldsymbol{\delta} & =\boldsymbol{\gamma}=\mathbf{0}, \\
\beta_{14} & =\beta_{16}=\alpha, \\
\beta_{15}+\beta_{14} & =1 \Longrightarrow \theta=1, \\
\beta_{21} & =1 \Longrightarrow \phi_{1}=1, \\
\beta_{24} & =0, \text { and } \beta_{26}=0,
\end{aligned}
$$

\footnotetext{
${ }^{5}$ We also estimated the VARX* model with $e_{0.75, t}$ and the foreign output variable constructed using fixed weights and obtained very similar estimates. These results are available upon request.

${ }^{6}$ The inclusion of the dummy variable changes the critical values of the test. The test statistics and the associated critical values are available on request.
} 
and re-estimating subject to the seven over-identifying restrictions we obtain

$$
\begin{aligned}
\theta & =1, \hat{\alpha}=\underset{(0.0647)}{0.2870}, \hat{\beta}_{13}=\underset{(12.57)}{-20.81,} \\
\phi_{1} & =1, \hat{\phi}_{2}=\underset{(14.94)}{-18.48}
\end{aligned}
$$

The LR statistic for testing all the 7 restrictions jointly is 24.02 which is to be compared to the bootstrapped critical values of 22.30 and 29.09 at $5 \%$ and $1 \%$ significance levels, respectively. Therefore, as before the restrictions are rejected at $5 \%$ level, but not at the $1 \%$ level. The estimates are fairly similar to the case when we do not include the war and revolution dummy, with the long run negative effects of inflation on real output still present, although now statistically less significant than previously. Table 3 reports the coefficient of the war and revolution dummy in the error correction equations where we observe that the war and revolution dummy is clearly insignificant at the 10 percent level in the real exchange rate and the inflation equations, while it is significant at the 10 percent level for the real money equation and significant at the 5 percent level in the output equation. These estimates suggest only a modest average decline in real output due to revolution and war, once the effects of the declines in real oil exports are taken into account.

\section{Table 3: Reduced-form error correction equations of the VECX*}

\begin{tabular}{llccc}
\hline Equation & $\Delta y_{t}$ & $\Delta m p_{t}$ & $\Delta \pi_{t}$ & $\Delta e p_{t}$ \\
\hline & & & & \\
WR Dummy & $-0.016993^{*}$ & $-0.0086472^{* *}$ & 0.0045923 & 0.0078659 \\
& $(0.0063355)$ & $(0.0047351)$ & $(0.0039030)$ & $(0.026624)$ \\
\hline
\end{tabular}

Notes: ${ }^{*}$ denotes significance at the 5 percent level and ${ }^{* *}$ denotes significance at the 10 percent level.

This point is clearly illustrated using Figure 8 which shows the significant drop in oil exports in the aftermath of the revolution, which only begins to recover in a sustained manner after the end of the war with Iraq. In effect, the decline in oil exports, partly due to the economic disruptions, in turn puts further downward pressure on the real economy. Although the price of oil declined slightly and steadily between 1979 and 1986, this was not the case for Iranian revenues from oil exports which drop significantly after the revolution and again at the start of the Iran-Iraq war while on the other hand was at a higher level than the price of oil after the war. Thus, the negative effects of the war and revolution is largely picked up by the oil export variable, $x o_{t}$.

However, if we had followed the literature and instead of total revenue from oil exports, $x o_{t}$, used the nominal price of oil, $p_{t}^{o}$, in our model, then the war and revolution dummy would have been necessary for modelling the disruptive effects of the revolution and the war on the real economy. In the light of these observations, we will work with the model with the $x o_{t}$ variable included, but without the the war and revolution dummy. 


\section{Figure 8: Price of oil and revenue from oil exports (xo)}

\section{Log level}

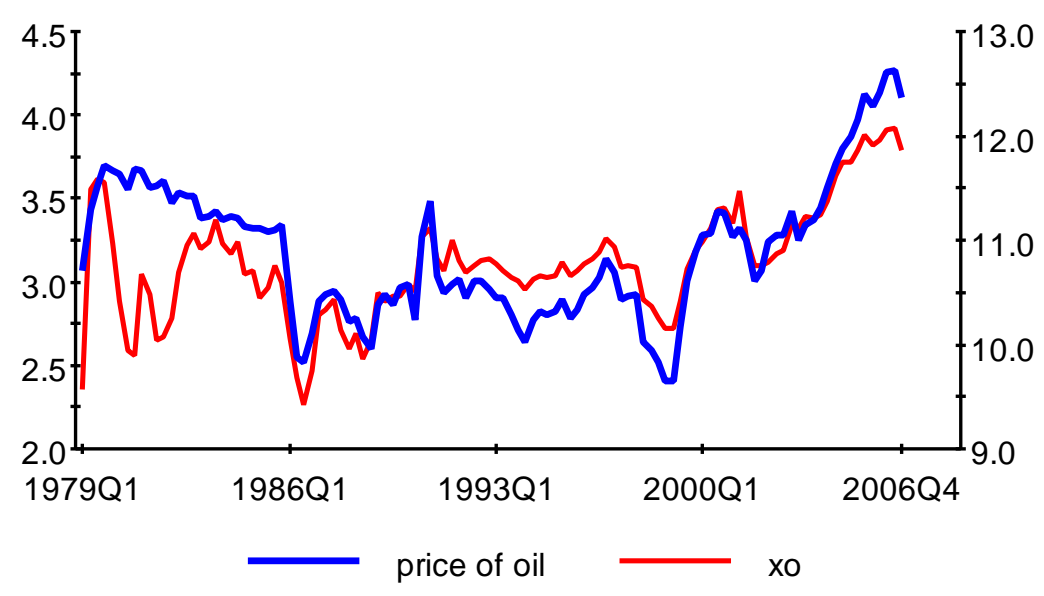

\subsubsection{Import Weights as Opposed to Trade Weights}

We also estimated our model with foreign output computed using import weights, both fixed and time-varying, rather than trade weights. The cointegration rank test statistics for the $\operatorname{VARX}^{*}(2,1)$ model with the data vector defined by $\mathbf{z}_{t}=\left\{y_{t}, m p_{t}, \pi_{t}, e p_{t}, y_{t, I M}^{*}, x o_{t}\right\}$, where $y_{t, I M}^{*}$ is real foreign output using time-varying import weights, again suggest the presence of two long run relations. Imposing the same 7 over-identifying restrictions as before and re-estimating we obtain

$$
\begin{aligned}
\theta & =1, \hat{\alpha}=\underset{(0.0487)}{0.2702}, \hat{\beta}_{13}=\underset{(4.20)}{-13.79,} \\
\phi_{1} & =1, \hat{\phi}_{2}=\underset{(6.47)}{-16.02}
\end{aligned}
$$

The LR statistic for testing all the 7 restrictions jointly is now 28.65 which is to be compared to the bootstrapped critical values of 21.79 and 30.43 at $5 \%$ and $1 \%$ significance levels, respectively. The results are very similar to the ones reported in the above Sub-sections, and shows that the choice of the weights in the construction of the foreign variable is of second order importance. However, given the important changes that have taken place in the geographical composition of the Iranian foreign trade since the revolution, gradually shifting Iran's trade from the West to the East, in what follows we use the time-varying trade weights as in Section 5.2.

\section{Short Run Dynamics}

The estimated model can also be used to examine the dynamic responses of the Iranian economy to various types of shocks, in particular shocks to oil exports and foreign output. 
Initially, we consider the effects of system wide shocks on the cointegrating relations using the persistence profiles, developed by Lee and Pesaran (1993) and Pesaran and Shin (1996). On impact the persistence profiles (PP) are normalized to take the value of unity, but the rate at which they tend to zero provide information on the speed with which equilibrium correction takes place in response to shocks. The PP could initially over-shoot, thus exceeding unity, but must eventually tend to zero if the long run relationship under consideration is cointegrating. To investigate the effects of variable specific shocks on the Iranian economy we make use of the Generalized Impulse Response Functions (GIRFs), developed in Koop, Pesaran, and Potter (1996) and Pesaran and Shin (1998). Unlike the orthogonalized impulse responses popularized in macroeconomics by Sims (1980), the GIRFs are invariant to the ordering of the variables in the VARX* model.

\subsection{Persistence Profiles}

Figure 9 depicts of the effect of a system-wide shock to the cointegrating relations with 95 percent bootstrapped confidence bounds. The speed of convergence to equilibrium for the two cointegrating relations are quite fast as compared, for example, with the UK (Garratt, Lee, Pesaran, and Shin (2006)) and Switzerland (Assenmacher-Wesche and Pesaran (2008)). The half life of the shock is less than one quarter and the life of the shock is generally less than eight quarters. Thus the effect of shocks tend to disappear rather quickly. This could be due to lack of access to capital markets and an absence of a developed domestic capital and money markets, which allows little possibility for shock absorptions. The recently created Oil Stabilization Fund could, in principle, if used appropriately act as a shock absorber which might lead to a more sluggish response of the economy to shocks.

\subsection{Generalized Impulse Responses}

Generalized Impulse Response Functions (GIRFs) can be computed for shocks to any of the variables in the model, but they are more straightforward to interpret in the case of shocks to the exogenous variables, namely oil exports and foreign output. Consider first the GIRFs of a unit shock (equal to one standard error) to oil exports given in Figure 10. These figures clearly show that a positive shock to oil exports significantly increases inflation, strengthens the real exchange rate $\left(e_{t}-p_{t}\right)$, increases real output, but its effect on real money balances whilst positive it is not statistically significant. These results are as to be expected, but also show that the effects of the shock work themselves through the economy rather rapidly. Note also that these effects tend to be permanent, due to the presence of unit roots in the underlying variables. Quantitatively, the positive oil export shock increases inflation by 0.8 percent per annum, real output by 3.2 percent and results in a real exchange rate appreciation of around 7.6 percent. The rise in the real exchange rate in the aftermath of the positive shock to oil exports can also be viewed as supporting the Dutch disease, although here the rise in the real exchange rate is in fact accompanied with a rise in real output which does not sit comfortably with those that view the Dutch disease as a resource curse. ${ }^{7}$

\footnotetext{
${ }^{7}$ For a short run macroeconomic analysis where a rise in oil exports induces a rise in real output see Pesaran (1984).
} 
Figure 9: The persistence profiles of the effect of a system-wide shock to the cointegrating relations with 95 percent bootstrapped confidence bounds

Output equation

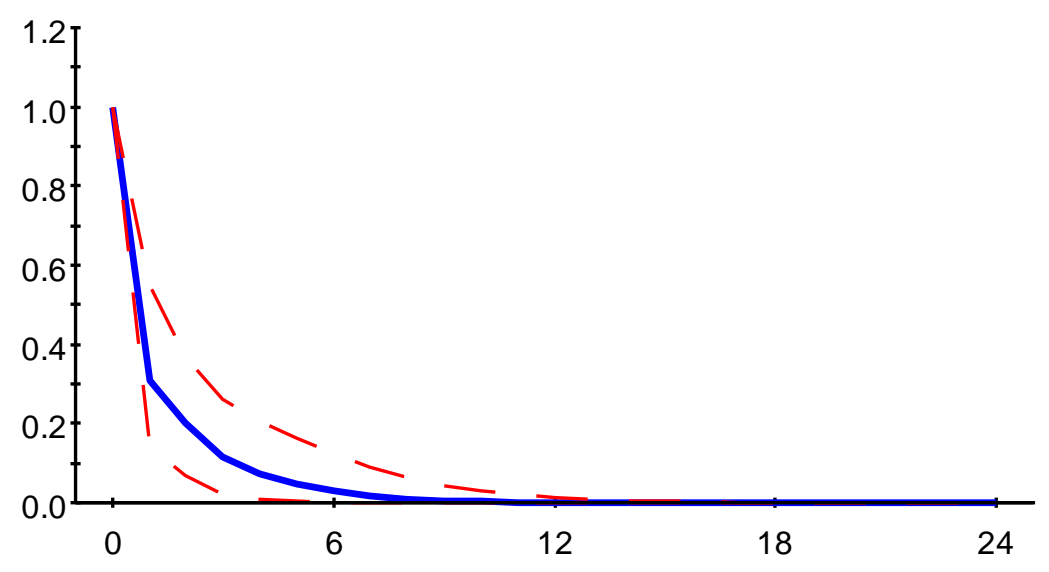

Money demand equation

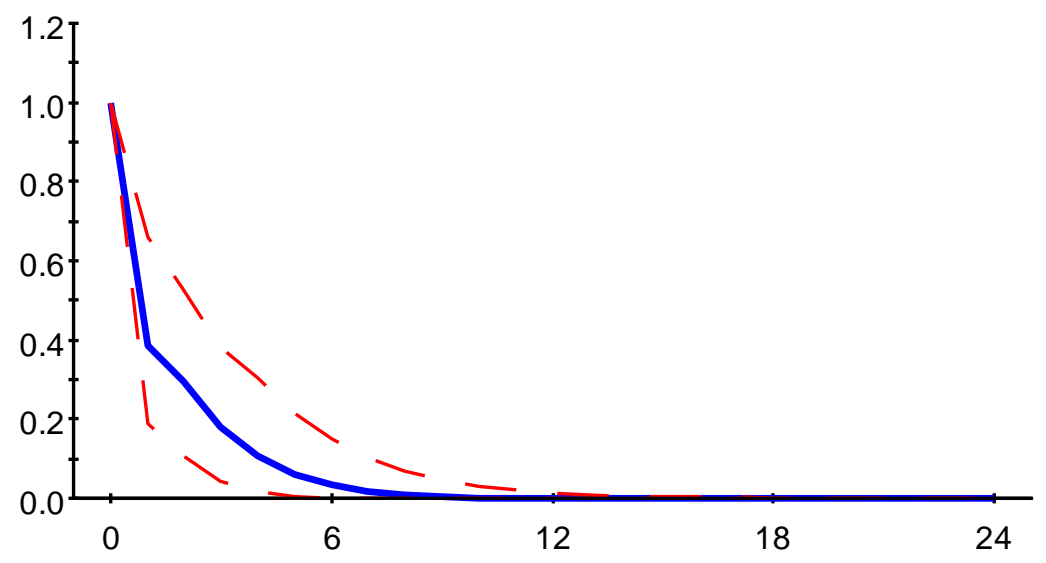


Figure 10: Generalized Impulse Responses of a positive unit shock to oil export revenues (with 95 percent bootstrapped confidence bounds)

Domestic inflation (dp)

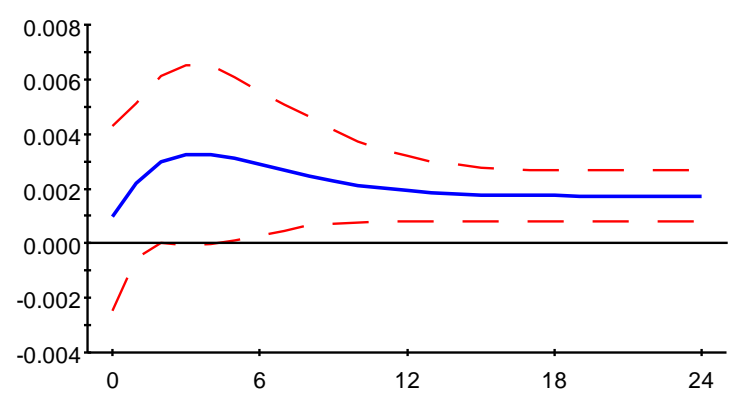

Domestic real money (mp)

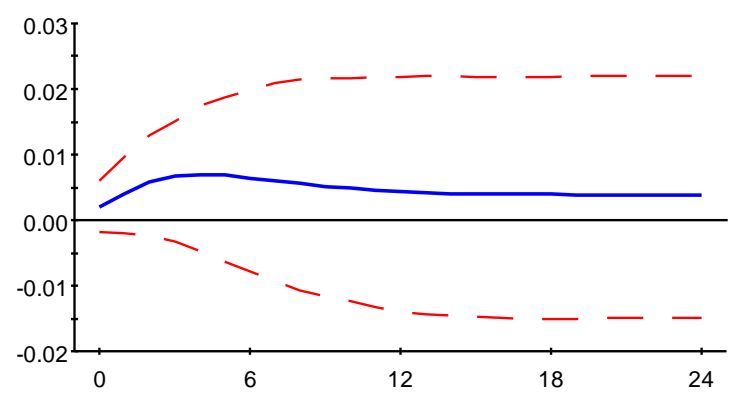

Domestic revenue from oil exports

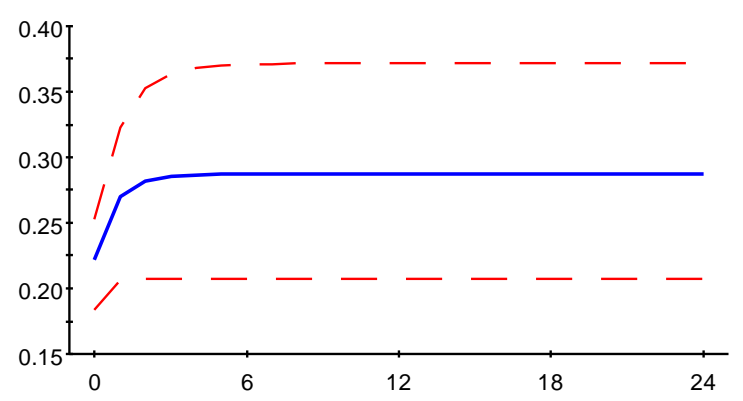

Domestic real exchange rate (ep)

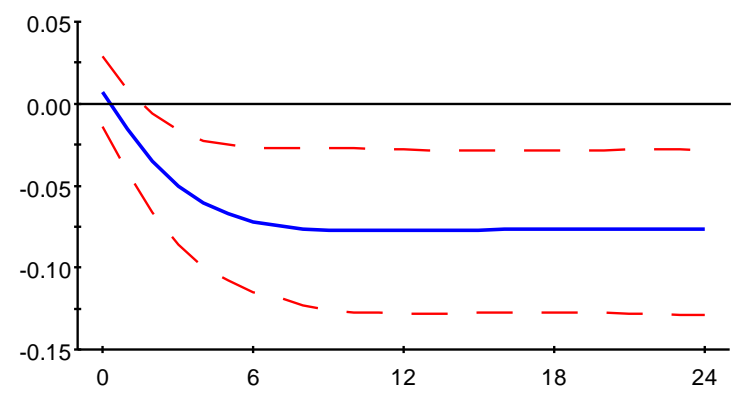

Domestic output (y)

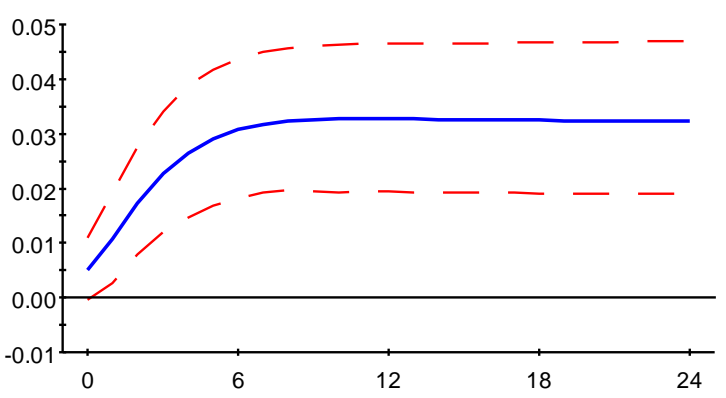


The GIRFs of a unit shock to foreign output are given in Figure 11. By comparison to the oil export shock these effects are muted and are generally insignificant statistically. By far the most important effect of the foreign output shock is on the real exchange rate, which appreciates by 2 per cent and is statistically significant for the first 3-4 quarters after the shock.

Figure 11: Generalized Impulse Responses of a positive unit shock to foreign output (with 95 percent bootstrapped confidence bounds)

Domestic inflation (dp)

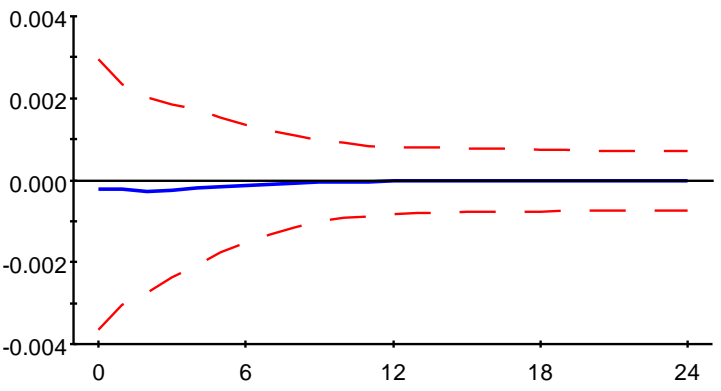

Domestic real money $(\mathrm{mp})$

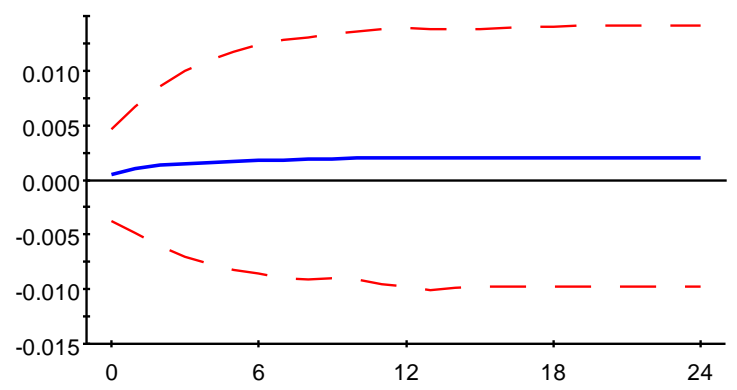

Domestic revenue from oil exports $(\mathrm{xo})$

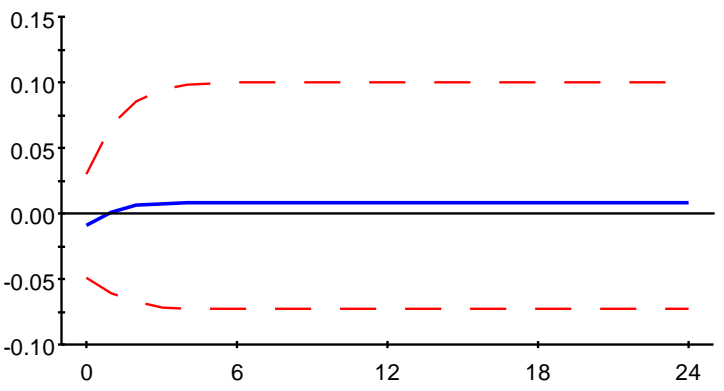

Domestic real exchange rate (ep)

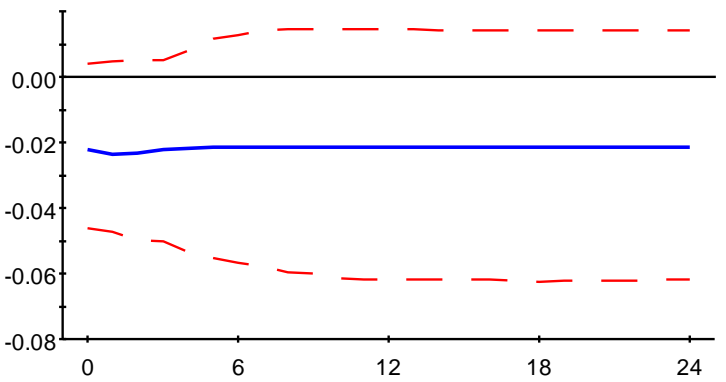

Domestic output $(\mathrm{y})$

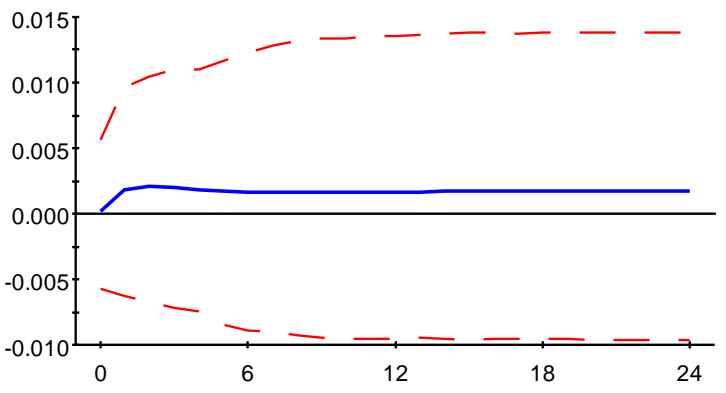

\subsection{Error-correcting Equations}

Using the estimates of the conditional model, (30), the error-correcting property of the model can also be seen in the size and significance of the coefficients of the error correcting 
terms, $\boldsymbol{\xi}_{t}=\left(\xi_{t, y}, \xi_{t, m p}\right)^{\prime}$, defined by (26). The estimates of the reduced form error correction equations are given in Table 4 , from which we can see that $\hat{\xi}_{t-1, y}$ and $\hat{\xi}_{t-1, m p}$ are both statistically significant in the output and real exchange rate equations but not in the real money and inflation equations. There seems to be a dichotomy between the real and the financial sides of the economy as far as their responses to disequilibria are concerned with the real output and real exchange rate adjusting most to shocks.

\section{Table 4: Reduced-form error correction equations of the VECX*}

\begin{tabular}{|c|c|c|c|c|}
\hline$\overline{\text { Equation }}$ & $\Delta y_{t}$ & $\Delta m p_{t}$ & $\Delta \pi_{t}$ & $\Delta e p_{t}$ \\
\hline$\hat{\xi}_{u, t-1}$ & $0.089^{*}$ & 0.026 & 0.028 & $-0.401^{*}$ \\
\hline $\begin{array}{l}\hat{r}_{\hat{r}}, t-1 \\
\hat{\hat{c}}\end{array}$ & $\begin{array}{l}(0.029) \\
-0.047^{*}\end{array}$ & $\begin{array}{c}(0.021) \\
0.011)\end{array}$ & $\begin{array}{l}(0.018) \\
-0.008\end{array}$ & $\begin{array}{l}(0.118) \\
0.332^{*}\end{array}$ \\
\hline$\xi_{m p, t-1}$ & $(0.023)$ & $(0.017)$ & $(0.014)$ & $\begin{array}{l}0.002 \\
(0.093)\end{array}$ \\
\hline$\Delta y_{t-1}$ & $0.325^{*}$ & 0.086 & -0.038 & -0.184 \\
\hline$\Delta m n$ & $\begin{array}{l}(0.094) \\
-0.515^{*}\end{array}$ & $\begin{array}{c}(0.069) \\
0.052\end{array}$ & $\begin{array}{c}(0.058) \\
0.061\end{array}$ & $\begin{array}{c}(0.386) \\
0.542\end{array}$ \\
\hline$\Delta m p_{t-1}$ & $(0.174)$ & $(0.128)$ & $(0.106)$ & $(0.711)$ \\
\hline$\Delta \pi_{t-1}$ & -0.021 & $0.232^{* *}$ & -0.143 & 0.335 \\
\hline$u_{t-1}$ & $(0.167)$ & $(0.123)$ & $(0.102)$ & $(0.681)$ \\
\hline$\Delta e p_{t-1}$ & $\begin{array}{l}-0.082 \\
(0.023)\end{array}$ & $\begin{array}{l}-0.017) \\
(0.017)\end{array}$ & $\begin{array}{l}-0.001 \\
(0.014)\end{array}$ & $\begin{array}{l}-0.042 \\
(0.094)\end{array}$ \\
\hline$\Delta u^{*}$ & 0.073 & 0.111 & -0.036 & $-4.162^{* *}$ \\
\hline & $(0.547)$ & $(0.402)$ & $(0.334)$ & $(2.235)$ \\
\hline$\Delta x o_{t}$ & $\begin{array}{l}0.023^{* *} \\
(0.014)\end{array}$ & $\begin{array}{l}0.009 \\
(0.010)\end{array}$ & $\begin{array}{l}0.004 \\
(0.008)\end{array}$ & $\begin{array}{l}0.027 \\
(0.056)\end{array}$ \\
\hline & $-0.363^{*}$ & -0.005 & -0.089 & $2.157^{*}$ \\
\hline intercept & $(0.144)$ & $(0.106)$ & $(0.088)$ & $(0.591)$ \\
\hline $\bar{R}^{2}$ & 0.189 & 0.226 & 0.138 & 0.085 \\
\hline $\bar{R}^{2}-A R(p)$ & $\begin{array}{c}0.054 \\
(p=1)\end{array}$ & $\begin{array}{c}0.158 \\
(p=2)\end{array}$ & $\begin{array}{c}0.141 \\
(p=2)\end{array}$ & $\begin{array}{l}0.00 \\
(p=1)\end{array}$ \\
\hline$S C: \chi^{2}(4)$ & 0.71 & 7.95 & 11.74 & 8.17 \\
\hline$F F: \chi^{2}(1)$ & 3.49 & 0.57 & 2.18 & 11.27 \\
\hline$N: \chi^{2}(2)$ & 1.97 & 2.96 & 9.56 & 3354.6 \\
\hline$H S: \chi^{2}(1)$ & 0.22 & 3.45 & 9.55 & 19.91 \\
\hline
\end{tabular}

Notes: The two error correction terms are given by:

$$
\begin{aligned}
& \xi_{y, t}=y_{t}+\underset{(4.37)}{13.84 \pi_{t}}-\underset{(0.0489)}{0.2647 e p_{t}}-\underset{(0.0489)}{0.7353} y_{t}^{*}-\underset{(0.0489)}{0.2647} x o_{t} \\
& \xi_{m p, t}=m p_{t}-y_{t}+\underset{(6.79)}{16.37 d p_{t}}
\end{aligned}
$$

${ }^{*}$ denotes significance at the 5 percent level and ${ }^{* *}$ denotes significance at the 10 percent level. SC is a test for serial correlation, FF a test for functional form, $\mathrm{N}$ a test for normality of the errors and HS a test for heteroscedasticity. Critical values are 3.84 for $\chi^{2}(1), 5.99$ for $\chi^{2}(2)$ and 9.49 for $\chi^{2}(4)$. $\bar{R}^{2}$ is the adjusted squared multiple correlation coefficient, and $\bar{R}^{2}-\mathrm{AR}(\mathrm{p})$ refers to the $\bar{R}^{2}$ of a univariate autoregressive equation. The sample period is 1979Q1 to 2006Q4.

Turning to the fit of the error-correcting equations, the inflation and the real money balances equations seem to be the least satisfactory. In the case of the inflation equations none of the regression coefficients are statistically significant and it suffers from residual 
serial correlation. ${ }^{8}$ In the case of the real money balances the only significant coefficient is that of the lagged inflation which is significant at the 10 percent level. The fit of the real exchange rate equation seems reasonable, considering the general unpredictably of exchange rates documented in the literature. By contrast the output equation provides a reasonable explanation, particularly considering the significant disruptions experienced by the Iranian economy over the period under study and the fact that no dummy variables are included in the regressions.

To evaluate the importance of the error correction terms we also estimated univariate autoregressive moving average (ARMA) time series equations for the four endogenous variables in the VARX* model and concluded that an $A R(1)$ specification fits best for the real output growth $\left(\Delta y_{t}\right)$, and the real exchange rate changes $\left(\Delta e p_{t}\right)$, and an $A R(2)$ specification for changes in inflation $\left(\Delta \pi_{t}\right)$ and real money balances $\left(\Delta m p_{t}\right)$. The adjusted squared multiple correlation coefficient of these univariate equations are denoted by $\bar{R}^{2}-A R(p)$, which needs to be compared to the $\bar{R}^{2}$ of the error correction equations also presented in Table 4. It is clear that the fit of the ECM equation for output at 19 percent is substantially better than the fit of the associated univariate $\mathrm{AR}(1)$ equation of only 5.4 percent. The ECM of the real exchange rate (at 8.5 percent) also fits much better than the univariate equation (at 0 percent). By contrast the ECM equations for inflation and the real money balances are either worse or not that much better than the univariate alternatives. This seems to be largely due to the fact that the univariate specifications point to a higher order dynamics for these variables. Unfortunately the available data does not allow us to experiment with a $\operatorname{VARX}^{*}(3,1)$ or $\operatorname{VARX}^{*}(3,2)$ specifications that might be needed to accommodate such higher order dynamics.

The actual and fitted values for each of the four equations together with the associated residuals are displayed in Figures 12 . We observe that while there are some large outliers, especially for the exchange rate equation in the mid 1980's and the beginning of the 1990's and for output and real money in the early 1990's, the fitted values seem to track the main movements of the dependent variables reasonably well. The presence of large outliers are reflected in the massive rejection of the normality of the errors in the case of the real exchange rate equation.

\footnotetext{
${ }^{8}$ The inflation equation also seems to suffer from multicollinearity since despite the fact that none of its coefficients are statistically significant the overall fit of the equation is highly significant.
} 
Figure 12: Actual, fitted, and residuals for the core equations

(a) Output equation

Actual and fitted

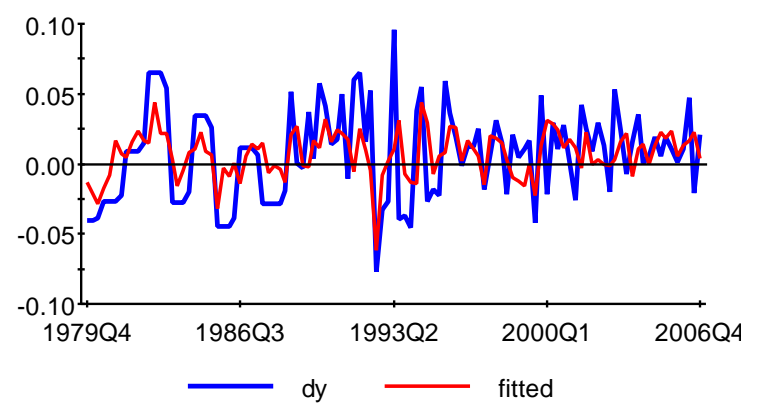

(b) Real money demand equation

Actual and fitted

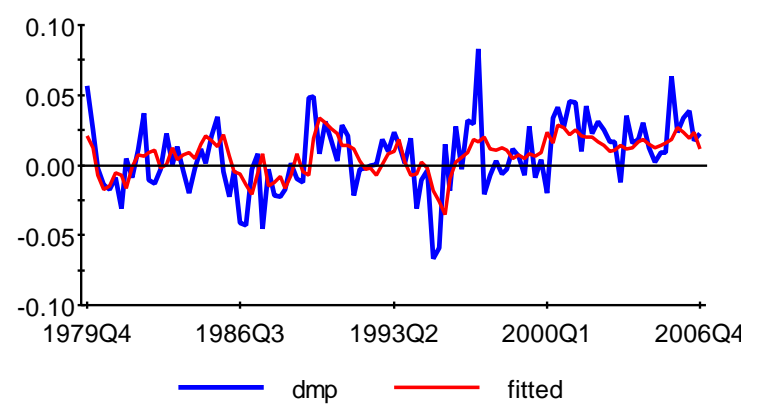

(c) Inflation equation

Actual and fitted

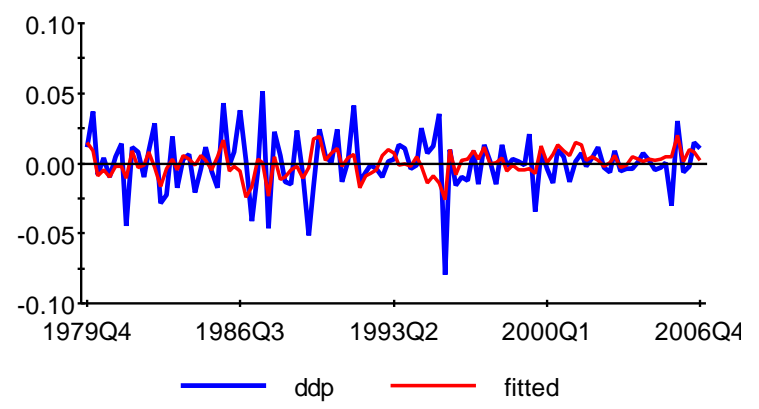

(d) Real exchange rate equation

Actual and fitted

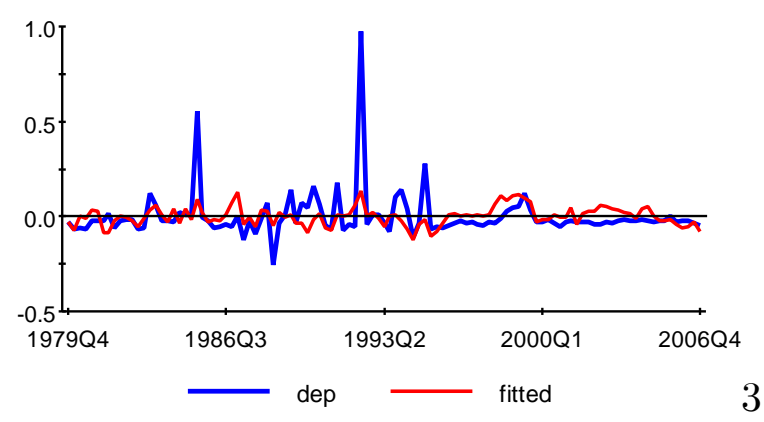

Residuals

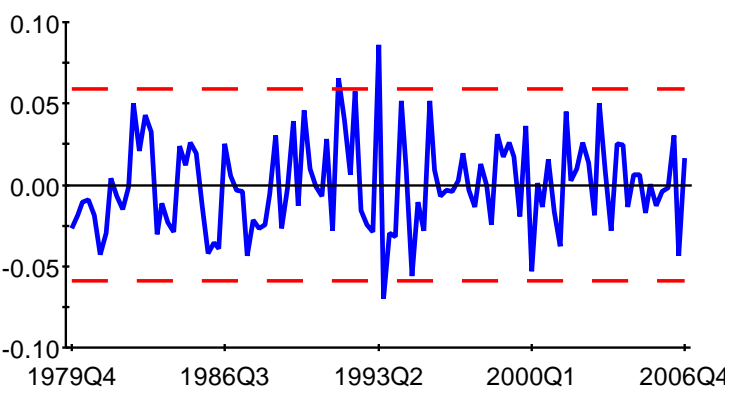

Residuals

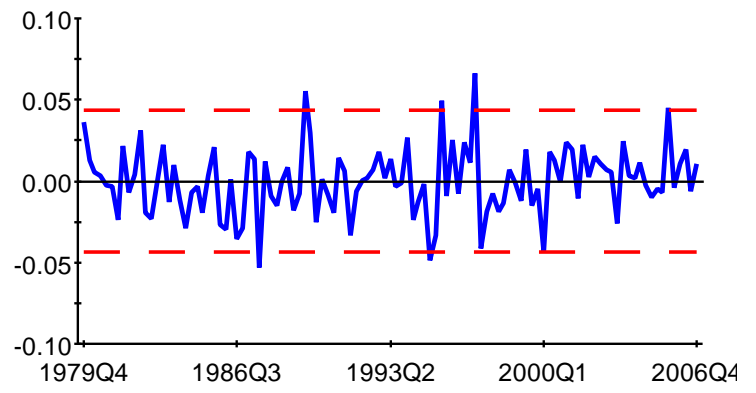

Residuals

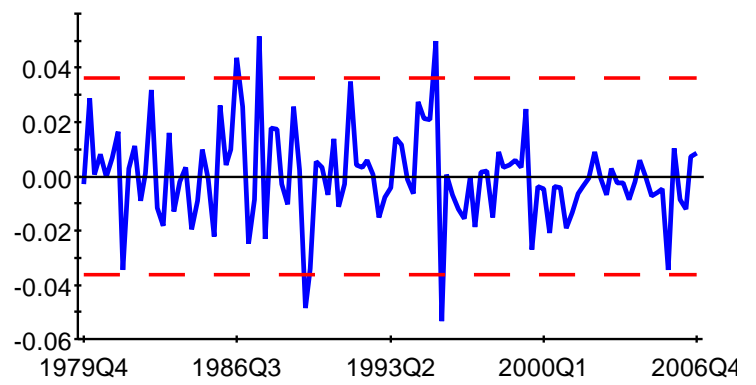

Residuals

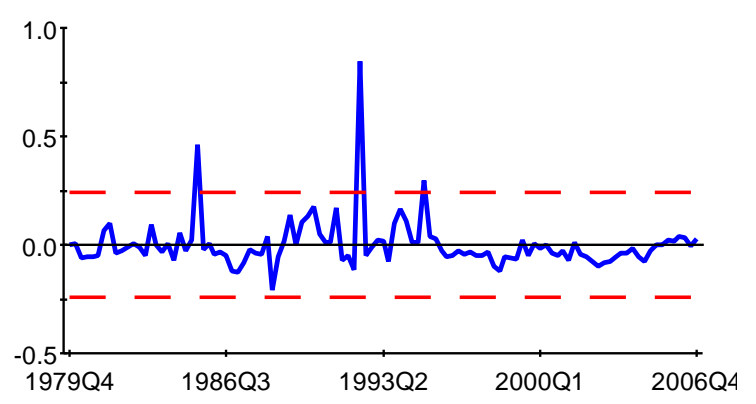




\section{Concluding Remarks}

This paper makes a theoretical contribution by showing the conditions under which income from a resource can have a lasting impact on growth and per capita income. Using this theoretical insight, it provides a small quarterly model of the Iranian economy, as an example of a major oil exporting economy, where the long run implications of oil exports for real output, inflation, real money balances, and the real exchange rate are tested. The results are generally supportive of the long run theory, although they point to certain inefficiencies in the demand management of the economy that manifest themselves as a significantly negative effect of inflation on real output, even in the long run. The estimates also suggest a rather rapid response of the economy to shocks, which could be due to the relatively underdeveloped nature of the money and capital markets in Iran. Such markets tend to act as shock absorbers in developed economies during normal conditions, although as we have seen recently, they can also act as shock magnifiers during crisis periods.

The research in this paper can be extended in a number of directions. The current VARX $^{*}$ model is connected to the rest of the world through oil exports and foreign real output. Although these are clearly the most important channels of the transmission of shocks to the Iranian economy, there could be others. It would be interesting to see if the model can be linked to the global model recently developed in Dees, di Mauro, Pesaran, and Smith (2007), where the differential effects of supply and demand shocks and different regional shocks on the Iranian economy could be investigated.

It would also be of interest to investigate the extent to which the long run effects of oil exports on real output documented in this paper can be found in the case of other major oil exporters. However, to obtain a sufficiently long quarterly series, and to take into account the particular institutional features of these economies, will present some challenges. The theoretical results of the paper can also be extended to allow for interactions between the oil and non-oil sectors and the short term effects of oil price volatility. Such an extension could, for example, help shed light on the importance of the recently established Oil Stabilization Fund in Iran or the sovereign wealth funds formed in other oil exporting countries as shock absorbers. 


\section{Appendix A: Macroeconometric Models of the Iranian Economy - A Survey of the Literature}

The origins of macro-econometric modeling in Iran date back to the early 1970's, when Habib-Agahi $(1971)^{9}$ pioneered the practice at the Iranian Plan and Budget Organization (PBO). Habib-Agahi's model contained 8 linear behavioral relations and 7 accounting identities, linking 3 categories of imports, aggregate output, real disposable income, private and government consumption and investment expenditures to the size of the development budget, oil and non-oil exports, and foreign loans for development. The model was estimated using annual time series data over the 1959-1970 period, and formed the basis of the first "official" macro-econometric model to be developed by the PBO. This was a modest exercise in macro-econometric modeling, largely reflecting the data and computational limitations prevailing in Iran at the time.

Looking to other models subsequently developed at the PBO, a distinction needs to be made between the models that were constructed before the 1979 revolution and those constructed afterwards. The first model developed at the PBO before the revolution was a modification of Habib-Agahi's model and related non-oil exports to the value added in agriculture instead of treating it as exogenous. However, the value added in agriculture was now assumed to be exogenous. The second major macro-econometric model constructed at the PBO before the revolution was much more detailed, and represented important advances over the earlier one. It allowed for the effect of relative prices on imports and non-oil exports demands, contained equations for the determination of a number of key monetary aggregates and tax revenues, and used a Phillips type wage equation to close the model. The model was estimated over the period 1961-1975 and was the first serious empirical attempt at modeling the interactions of the monetary and real variables in the Iranian economy. However, as with the other models developed for the Iranian economy there is no systematic documentation of the model's short run predictive performance or its long run properties.

Perhaps not surprisingly, revolution and the subsequent eight-year war with Iraq halted any serious development of macro-econometric models both inside and outside of the PBO. But with the ending of the Iran-Iraq war in 1988, and the government's attempt at regeneration and reconstruction of the economy, once again the problem of economic planning and the development of appropriate macro-econometric models gained priority. But although the importance of macro-econometric models was recognized in the formulation of the First Five-Year Development Plan (1990-94), given the urgency surrounding the formulation of the First Plan and the limited time available to accomplish the task, serious attempts at macro-econometric modeling had to wait until after its approval and implementation.

According to official accounts, two different macro-econometric models were utilized in the formulation of the Second Five-Year Development Plan. ${ }^{10}$ The first model, PBO1, contains 25 econometrically estimated behavioral, technical, and institutional relations and a

\footnotetext{
${ }^{9}$ The dates in the 1300s are based on the Iranian calendar. The corresponding Gregorian dates are roughly equal to the Iranian date plus 621. Publications in Persian are cited with the Gregorian dates in the text but with both the Iranian and the Georgian calendar dates in the references.

${ }^{10}$ See PBO (1993). Initially the implementation of the Second Five Year Development Plan was intended to commence in March 1994, but due to delay in its approval by the Iranian Parliament was postponed by one year.
} 
number of accounting identities. With a few exceptions these relations are estimated by the least squares methods over the period 1974-1993, and are documented in PBO (1993). ${ }^{11}$ This model is composed of a production and factor demand module, a Keynesian incomeexpenditure flow module, with investment expenditures disaggregated by 10 major production sectors, and an aggregate price equation. The second model developed seems to represent an extension of the first.

In addition to these models used for Iran's development plans, a number of other macroeconometric models have been developed for Iran since the contribution of Habib-Agahi in the beginning of the 1970's, both at the PBO and by other researchers around the world. Prominent examples of the latter category are the models developed by Baharie (1973), Vakil (1973), Shahshahani-Madani (1978), Heiat (1986) and Safai (1986). These models differ in the extent of detail and the level of disaggregation, but are very similar in their underlying structures. They are largely demand-determined Keynesian models, and with a few minor exceptions neglect the effect of relative prices and stock-flow relations on the economy's evolution. Also, very little is known about their short run forecasting performance, or their long-term properties. In contrast to these papers, Noferesti and Arabmazar (1993) develop a model in which aggregate supply is not assumed to be perfectly elastic, while Valadkhani (1997), building on the work of the above-mentioned papers, develops a more comprehensive macroeconometric model for Iran.

There are also a number of simple planning/optimal control models developed notably by Motaman (1979), Razavi (1982), and Razavi (1983) for the analysis of the optimal rate of oil production in oil-based economies. These models are primarily concerned with the intertemporal optimization problem involved in oil production decisions (namely, whether to produce now or later), and are typically very simple as far as their main structural relations are concerned. They are not intended as forecasting or budgetary tools and, in view of the current constraints on Iran's capacity to produce oil, have limited relevance to Iran's economic policy problems.

An alternative strategy to the models developed in the above mentioned papers would be to estimate vector autoregressive (VAR) models in some of the main macroeconomic variables, such as output, price level, money supply, oil exports, consumption, and investment, along the lines originally developed by Sims (1980). In more recent papers, Mehrara and Oskoui (2007) make use of a structural VAR to determine whether oil price shocks are the main source of output fluctuation for Iran, while Elyasiani and Zhao (2008) make use of vector autoregression, generalized impulse response function and generalized variance decomposition techniques to determine the interdependencies of Iran with its major trading partners and the US. But the use of VAR models, without imposition of structural relations on their long run solutions, will be limited to short-term forecasting and are unlikely to be relevant for medium term policy analysis. Thus, a long run structural approach to VAR modeling and its application to the Iranian economy, which we take up in this paper, are worth pursuing.

Other papers of interest dealing with economic growth in Iran are those of Valadkhani (2006), which looks at the determinants of the growing unemployment rate in Iran, Pahlavani, Wilson, and Worthington (2005), which tries to identify the short and long run deter-

\footnotetext{
${ }^{11}$ The relations in the published version of model PBO1 were mainly estimated over the period 1974-1992.
} 
minants of growth, taking into account the endogenously identified structural breaks in Iran, and Becker (1999), which looks at the development of several variables from pre- to postrevolution and the effect of monetary shocks on these variables. Bahmani-Oskooee (1995) and Kia (2006) explore the determinants of inflation in Iran, taking into account the role external factors.

While all the papers discussed so far have made use of annual data, there are a few IMF working papers on Iran using quarterly data. In particular, Bonato (2008) looks at the determinants of inflation in Iran, Celasun and Goswami (2002) develop an econometric model of short run inflation and long run money demand dynamics in Iran, and Liu and Adedeji (2000) construct a model to develop the determinants of inflation in Iran. However, all of the papers using quarterly data focus on a certain aspect of the Iranian economy, for instance the money demand relation or the determination of inflation, and as such do not consider the interconnection of the domestic variables with that of foreign variables. Neither do they explore the short run and the long run channels of growth. Part of our contribution has then been to make use of quarterly data, while exploring the interconnection between the Iranian economy and the rest of the world and paying attention to both the short and long run channels through which oil export revenues effect growth.

\section{Appendix B: Sources and Construction of the Data}

\section{Domestic and Foreign Data Series}

Our data set contains quarterly observations on Iran and another 33 countries, from the first quarter of 1979 to the fourth quarter of 2006. The domestic variables included are $(\log )$ real output, $y_{t},(\log )$ real money supply, $m p_{t}$, (log) price level, $p_{t}$, the rate of inflation, $\pi_{t}=p_{t}-p_{t-1}$, and (log) nominal exchange rate, $e_{t}$. Specifically

$$
\begin{aligned}
y_{t} & =\ln \left(G D P_{t} / C P I_{t}\right), & m p_{t} & =\log \left(M_{t} / C P I_{t}\right), \\
e_{t} & =\ln \left(E_{t}\right), & p_{t} & =\ln \left(C P I_{t}\right),
\end{aligned}
$$

where $G D P_{t}$ is the nominal Gross Domestic Product, $M_{t}$ is a broad liquidity measure that includes M1 and Quasi Money, $C P I_{t}$ is the consumer price index, and $E_{t}$ is the number of rials per one US dollar exchanged on 'free' markets.

The two exogenous variables in the model are foreign output, $y_{t}^{*}$, and oil income in US dollars defined as $x o_{t}=\ln \left(P_{t}^{o} X_{t}^{o}\right)$, where $P_{t}^{o}$ is the nominal price of oil per barrel in US dollars, and $X_{t}^{o}$ is the domestic oil export in thousands of barrels per day. Foreign output was computed as the trade weighted average of log real output indices $\left(y_{j t}\right)$ of Iran's trading partners:

$$
\begin{aligned}
y_{t}^{*} & =\sum_{j=1}^{33} \bar{\omega}_{j, t-1} y_{j t}, \text { time varying weights, } \\
y_{t, F W}^{*} & =\sum_{j=1}^{33} \omega_{j, 2001-03} y_{j t}, \text { fixed weights, }
\end{aligned}
$$


where $\omega_{j, 2001-03}$ and $\bar{\omega}_{j, t-1}$ are defined below by (33) and (34). The countries included in these weighted averages are: Argentina, Australia, Austria, Belgium, Brazil, Canada, China, Chile, Finland, France, Germany, India, Indonesia, Italy, Japan, Korea, Malaysia, Mexico, Netherlands, Norway, New Zealand, Peru, Philippines, South Africa, Saudi Arabia, Singapore, Spain, Sweden, Switzerland, Thailand, Turkey, United Kingdom, and United States.

The trade weights are computed based on the IMF Direction of Trade Statistics between 1980 and 2006. The bilateral trade of Iran with country $j$ during a given year $t$, denoted by $T_{j t}$, is calculated as the average of exports and imports of Iran with that country. Trade data for Belgium is only available from 1997, and so the trade shares for Belgium between 1980 and 1996 was calculated by using the data on Belgium-Luxembourg and multiplying it by 0.93 (this procedure was also adopted in Dees, di Mauro, Pesaran, and Smith (2007)). In addition, trade data between South Africa and partner countries are only available from 1998, and so the data of all trading partners with South Africa was used to construct the South African trade shares with partners between 1980 and 1997.

The fixed trade weights were computed over the period 2001-2003 and are given by

$$
\omega_{j, 2001-03}=\frac{T_{j, 2001}+T_{j, 2002}+T_{j, 2003}}{T_{2001}+T_{2002}+T_{2003}},
$$

where $T_{t}=\sum_{j=1}^{N} T_{j t}$, for $t=2001,2002,2003$. The time varying trade weights are computed as

$$
\bar{\omega}_{j t}=\frac{T_{j, t}+T_{j, t-1}+T_{j, t-2}}{T_{t}+T_{t-1}+T_{t-2}}
$$

We also considered three year moving averages of the the annual trade shares, $\omega_{j t}=T_{j t} / T_{t}$ and obtained very similar results.

The most important trading partner for Iran is Japan, which accounts for between 15 and 20 percent of the total Iranian trade. More than 40 percent of the Iranian trade originates in or is destined for the euro area economies with Germany, Italy and France being Iran's most important trading partners in Europe. ${ }^{12}$ Trade with China has increased significantly over the past two decades, emphasising the shift in the Iranian trade from the west to the east. Other countries in our data set with whom Iran's total trade is more than five percent are UK, Korea, and Turkey.

\section{Data Sources: Domestic Variables}

\section{Real Output}

The main source of data on Iran's real output is the Central Bank of the Islamic Republic of Iran (CBI) online database: Economic Time Series Database (http://tsd.cbi.ir/). Quarterly observations are available from 1988Q2 while annual data is available from 1959. We seasonally adjust the quarterly data using the U.S. Census Bureau's X-12 ARIMA seasonal

\footnotetext{
${ }^{12}$ When computing the trade weights and thus the foreign variables we aggregate Austria, Belgium, Finland, France, Germany, Italy, Netherlands, and Spain as the euro countries and so use their combined trade weight and output.
} 
adjustment program. ${ }^{13}$ Quarterly series were interpolated (backwards) linearly from the annual series using the same method as that applied by Dees, di Mauro, Pesaran, and Smith (2007) to data for a number of the 33 countries in their data set. This data source is also updated to end of 2006 and used for the computation of the foreign output variable described above. For a description of the interpolation procedure see Dees, di Mauro, Pesaran, and Smith (2007) Section 1.1 of Supplement A.

\section{Consumer Price Indices}

The CBI online database contains annual CPI data from 1959Q2 and quarterly data from 1990Q2. To complete the quarterly data series we make use of several volumes of the CBI's Economic Report and Balance Sheets. We first use the 1981, 1987, and the 1989 Economic Report and Balance Sheets to compute quarterly data between 1976 and 1989 from the monthly data available in these reports. We then obtain quarterly CPI series by splicing the three series of CPI such that our quarterly CPI data stretches from 1976Q2 to 2007Q1, setting the average value of the index for 2000 equal to 100. Finally, we seasonally adjust the quarterly data using the U.S. Census Bureau's X-12 ARIMA seasonal adjustment program.

\section{Exchange Rates}

We obtain the official exchange rate series from the CBI online database. This data is available from 1959Q2. The nominal 'market' or 'free' exchange rate series used is from the IMF INS database and is available from 1979Q1.

\section{Money and Quasi Money}

The data on money and quasi money supply are from the IMF IFS series 34 and 35 and are available from 1957Q1. As money supply data between 1984Q2 and 1986Q2 is missing in the IFS series, we obtained the complete series by splicing the IFS and CBI data on money supply. Quasi money data was missing for 1960Q4, 1978Q4, and between 1985Q2 to 1986Q2. Again we filled in for the missing data by splicing the IFS and the CBI data, but as CBI data was only available from 1974Q1, the complete series for quasi money is available only from 1961Q1.

We seasonally adjust the quarterly data on money and quasi money supply using the U.S. Census Bureau's X-12 ARIMA seasonal adjustment program.

\section{Oil Exports and Prices}

Annual and quarterly oil export (thousand barrels per day) are available, from 1973 and 1978Q2 respectively, from the CBI online database. Quarterly crude oil production is also available from the CBI online database.

Value added of oil group, Gross Domestic Product at Basic Prices, and Non-Oil Gross Domestic Product at Basic Prices are available annually from 1959 and quarterly from 1988Q2.

\footnotetext{
${ }^{13}$ For further information see U.S. Census Bureau (2007): X-12-ARIMA Reference Manual at http://www.census.gov/srd/www/x12a/
} 
We first seasonally adjust the quarterly data and then obtain quarterly series from 1959Q2 by linearly interpolating (backwards) the 'missing' quarterly series from the annual series

\section{Population}

The annual data on population was obtained from the IMF IFS series 99. This data was available from 1948. As quarterly data on population were not available, quarterly series were interpolated linearly from the annual series using the same method used to generate quarterly output series described above.

\section{Conversion from Iranian to Gregorian Years}

The Iranian year generally starts on the $21^{\text {st }}$ of March, as such the Iranian quarter 1 contains 10 days of the Gregorian quarter 1 and 80 days of Gregorian quarter 2. To convert the data from Iranian to Gregorian calendar we simply adopt the following rule: $G(Q)=\frac{8}{9} \operatorname{Iran}(Q-$ $1)+\frac{1}{9} \operatorname{Iran}(Q)$, where $G(Q)$ is the Gregorian quarter $Q$ and $\operatorname{Iran}(Q)$ is the Iranian quarter $Q$. More complex ways of calculating, such as taking into account exact number of days in the Iranian Quarter and converting the data was also investigated, but there were essentially no differences in the series.

\section{Appendix C: Unit Root Test Results}

To make sure that we make sensible interpretation of the long run relations and also to ensure that we do not work with a mixture of $I(1)$ and $I(2)$ variables we need to consider the unit root properties of the core variables in our model $\left(y_{t}, m p_{t}, \pi_{t}, e p_{t}, y_{t}^{*}, x o_{t}\right)$. Table 5 reports the standard Augmented Dickey-Fuller (ADF) test. But as the power of unit root tests are often low we also report the generalized least squares version of the Dickey-Fuller test (ADF-GLS) proposed by Elliott, Rothenberg, and Stock (1996) and the weighted symmetric ADF test (ADF-WS) of Park and Fuller (1995), as they both have been shown to have better power properties than the ADF test.

It is clear from Figures 2 to 6 that most of the core variables are trended and so we will include a trend and an intercept in the ADF regression for all the variables but $e p_{t}$ and $x o_{t}$, while we will only include an intercept in the ADF regressions applied to their differences and second differences. As can be seen from Table 5 both ADF and ADF-WS provides strong support that $y_{t}, m p_{t}, \pi_{t}, e p_{t}, y_{t}^{*}, x o_{t}$ are all $I(1)$, as the unit root hypothesis is clearly rejected when applied to the first differences of these variables while this is not the case for the unit root test applied to the levels. The ADF-GLS on the other hand gives less clear cut results but generally supports the rejection of unit roots in the first difference of the core variables. Thus we can safely regard all the core variables as being I(1) and not worry about dealing with a mixture of $I(1)$ and $I(2)$ variables in our model. 


\section{Table 5: Unit root test statistics (based on AIC order selection)}

\begin{tabular}{|c|c|c|c|c|c|c|c|c|c|}
\hline \multicolumn{10}{|c|}{ Unit root test statistics for the levels } \\
\hline & $y_{t}$ & $p_{t}$ & $e_{t}$ & $e p_{t}$ & $m p_{t}$ & $y_{t}^{*}$ & $x o_{t}$ & $C V$ & $C V T$ \\
\hline $\mathrm{ADF}$ & -2.67 & -2.01 & -0.79 & -1.43 & -0.19 & -1.80 & -2.50 & -2.89 & -3.45 \\
\hline ADF-GLS & -1.29 & -2.01 & -1.08 & -1.37 & -0.68 & -2.02 & -1.10 & -2.14 & -3.03 \\
\hline ADF-WS & -1.48 & -2.06 & -1.02 & -1.72 & -0.59 & -2.12 & -3.09 & -2.55 & -3.24 \\
\hline \multicolumn{10}{|c|}{ Unit root test statistics for the first differences } \\
\hline & $\Delta y_{t}$ & $\Delta p_{t}$ & $\Delta e_{t}$ & $\Delta e p_{t}$ & $\Delta m p_{t}$ & $\Delta y_{t}^{*}$ & $\Delta x o_{t}$ & $C V$ & $C V T$ \\
\hline $\mathrm{ADF}$ & -8.42 & -3.82 & -10.35 & -10.45 & -4.31 & -3.37 & -8.36 & -2.89 & -3.45 \\
\hline ADF-GLS & -7.66 & -2.96 & -9.79 & -10.29 & -2.94 & -1.94 & -1.09 & -2.14 & -3.03 \\
\hline ADF-WS & -8.16 & -4.04 & -10.63 & -10.73 & -4.29 & -3.64 & -6.08 & -2.55 & -3.24 \\
\hline \multicolumn{10}{|c|}{ Unit root test statistics for the second differences } \\
\hline & $\Delta^{2} y_{t}$ & $\Delta^{2} p_{t}$ & $\Delta^{2} e_{t}$ & $\Delta^{2} e p_{t}$ & $\Delta^{2} m p_{t}$ & $\Delta^{2} y_{t}^{*}$ & $\Delta^{2} x o_{t}$ & $C V$ & $C V T$ \\
\hline $\mathrm{ADF}$ & -9.07 & -5.95 & -7.78 & -7.55 & -6.90 & $\begin{array}{l}-8.79 \\
-\end{array}$ & -10.12 & -2.89 & -3.45 \\
\hline ADF-GLS & -3.72 & -5.43 & -7.82 & -7.55 & -2.10 & -1.50 & -0.28 & -2.14 & -3.03 \\
\hline ADF-WS & -9.38 & -5.84 & -8.08 & -7.82 & -6.77 & -8.69 & -6.33 & -2.55 & -3.24 \\
\hline
\end{tabular}

Notes: ADF denotes the Augmented Dickey-Fuller Test, ADF-GLS the generalized least squares version of the ADF test, and ADF-WS the weighted least squares ADF test. The sample period runs from 1979Q1 to 2006Q4. CV T gives the 95 percent simulated critical values for the test with intercept and trend, while $\mathrm{C}$ is the 95 percent simulated critical values for the test including an intercept only.

\section{References}

Abadir, K., K. Hadri, and E. Tzavalis (1999). The Influence of VAR Dimensions on Estimator Biases. Econometrica 67, 163-181.

Amuzegar, J. (1997). Iran's Economy under the Islamic Republic. I.B. Tauris.

Amuzegar, J. (2008). Iran's Oil as a Blessing and a Curse. The Brown Journal of World Affairs 15, 46-61.

Assenmacher-Wesche, K. and M. H. Pesaran (2008). A VECX* Model of the Swiss Economy. Cambridge Working Papers in Economics 0809.

Baharie, N. (1973). Economic Policy and Development Strategy in Iran: A MacroSimulation Approach. Ph. D. thesis, University of Illinois, Illinois.

Bahmani-Oskooee, M. (1995). Source of Inflation in Post-Revolutionary Iran. International Economic Journal 9.2, 61-72.

Becker, T. (1999). Common Trends and Structural Change: A Dynamic Macro Model for the Pre- and Postrevolution Islamic Republic of Iran. IMF Working Paper WP/99/82.

Binder, M. and M. Pesaran (1999). Stochastic Growth Models and Their Econometric Implications. Journal of Economic Growth 4, 139-183. 
Bonato, L. (2008). Money and Inflation in the Islamic Republic of Iran. Review of Middle East Economics and Finance 4(1), Article 3.

BP (2009). BP Statistical Review of World Energy: June 2009. Beacon Press.

Brunnschweiler, C. N. and E. H. Bulte (2008). The resource curse revisited and revised: A tale of paradoxes and red herrings. Journal of Environmental Economics and Management 55(3), $248-264$.

Caselli, F. and T. Cunningham (2009). Leader behaviour and the natural resource curse. Oxford Economic Papers Forthcoming.

Celasun, O. and M. Goswami (2002). An Analysis of Money Demand and Inflation in the Islamic Republic of Iran. IMF Working Paper WP/02/205.

Collier, P. and A. Hoeffler (2004). Greed and grievance in civil war. Oxford Economic Papers 56, 563-595.

Corden, W. M. and J. P. Neary (1982). Booming Sector and De-Industrialisation in a Small Open Economy. The Economic Journal 92(368), 825-848.

Dees, S., F. di Mauro, M. H. Pesaran, and L. V. Smith (2007). Exploring The International Linkages Of The Euro Area: A Global Var Analysis. Journal of Applied Econometrics 22, $1-38$.

Elliott, G., T. J. Rothenberg, and J. H. Stock (1996). Efficient Tests for an Autoregressive Unit Root. Econometrica 64, 813-836.

Elyasiani, E. and W. Zhao (2008). International interdependence of an emerging market: the case of Iran. Applied Economics 40, $395-412$.

Esfahani, H. S. and M. H. Pesaran (2009). The Iranian Economy in the Twentieth Century: A Global Perspective. Iranian Studies 42, $177-211$.

Garratt, A., K. Lee, M. H. Pesaran, and Y. Shin (2003). A Long Run Structural Macroeconometric Model of the UK. Economic Journal 113, 412-455.

Garratt, T., K. Lee, M. H. Pesaran, and Y. Shin (2006). Global and National Macroeconometric Modelling: A Long Run Structural Approach. Oxford: Oxford University Press.

Gonzalo, J. (1994). Five alternative methods of estimating long-run equilibrium relationships. Journal of Econometrics 60(1-2), 203 - 233.

Gredenhoff, M. and T. Jacobson (2001). Bootstrap Testing Linear Restrictions on Cointegrating Vectors. Journal of Business and Economic Statistics 19, 63-72.

Habib-Agahi, H. (1971). A Macro Model for Iranian Economy: 1338-1349. Plan and Budget Organization, Tehran, Iran. 
Haug, A. (1996). Tests for cointegration A Monte Carlo comparison. Journal of Econometrics $71,89-115$.

Heiat, A. (1986). An Econometric Study of an Oil-Exporting Country: The Case of Iran. Ph. D. thesis, Portland State University, Portland, Oregon.

Kia, A. (2006). Deficits, debt financing, monetary policy and inflation in developing countries: Internal or external factors?: Evidence from Iran. Journal of Asian Economics 17(5), $879-903$.

Koop, G., M. H. Pesaran, and S. M. Potter (1996). Impulse Response Analysis in Nonlinear Multivariate Models. Journal of Econometrics 74, 119-147.

Krugman, P. (1987). The narrow moving band, the Dutch disease, and the competitive consequences of Mrs. Thatcher : Notes on trade in the presence of dynamic scale economies. Journal of Development Economics 27(1-2), 41 - 55.

Lane, P. R. and A. Tornell (1996). Power, growth, and the voracity effect. Journal of Economic Growth 1, 213-241.

Lee, K. and M. H. Pesaran (1993). Persistence Profiles and Business Cycle Fluctuations in a Disaggregated Model of UK Output Growth. Ricerche Economiche 47, 293-322.

Leite, C. and M. Weidmann (1999). Does Mother Nature Corrupt? Natural Resources,. Corruption and Economic Growth. IMF Working paper WP/99/85.

Liu, O. and O. Adedeji (2000). Determinants of Inflation in the Islamic Republic of Iran A Macroeconomic Analysis. IMF Working Paper WP/00/12\%.

Mahdavi, H. (1970). The patterns and problems of economic development in rentier states: The case of Iran. In M. Cook (Ed.), Studies in the Economic History of the Middle East. Oxford University Press, London, UK.

Mauro, P. (1995). Corruption and Growth. The Quarterly Journal of Economics 110(3), $681-712$.

Mehrara, M. and K. N. Oskoui (2007). The sources of macroeconomic fluctuations in oil exporting countries: A comparative study. Economic Modelling 24(3), 365 - 379.

Mojaver, F. (2009). Sources of economic growth and stagnation in Iran. The Journal of International Trade $\&$ Economic Development: An International and Comparative Review 18(2), 275-295.

Motaman, H. (1979). Expenditure of Oil Revenue: An Optimal Control Approach with Application to the Iranian Economy. Frances Pinter.

Neary, J. P. and S. J. G. van Wijnbergen (1986). Natural Resources and the Macroeconomy. MIT Press, Cambridge, MA. 
Noferesti, M. and A. Arabmazar (1374, 1993). A macroeconomic model for the Iranian economy (in Persian). Journal of Research and Economic Policies 2(1), 5-39.

Pahlavani, M., E. Wilson, and A. Worthington (2005). Trade-GDP Nexus in Iran: An Application of the Autoregressive Distributed Lag (ARDL) Model. Faculty of Commerce Papers 144, University of Wollongong.

Park, H. and W. Fuller (1995). Alternative Estimators and Unit Root Tests for the Autoregressive Process. Journal of Time Series Analysis 16, 415-429.

PBO $(1372,1993)$. Documentations of the Second Economic, Social and Cultural Development Plan of the Islamic Republic of Iran (1373-1377), Volume 5, (Macroeconomic Models and Models for Prediction of Population). Technical report, Plan and Budget Organization, Iran.

Pesaran, M. H. (1982). The System of Dependent Capitalism in Pre- and PostRevolutionary Iran. International Journal of Middle East Studies 14(4), 501-522.

Pesaran, M. H. (1984). Macroeconomic Policy in an Oil-Exporting Economy with Foreign Exchange Controls. Economica 51(203), 253-270.

Pesaran, M. H. (1992). The Iranian Foreign Exchange Policy and the Black Market for Dollars. International Journal of Middle East Studies 24(1), 101-125.

Pesaran, M. H. (2000). Economic Trends and Macroeconomic Policies in Post-Revolutionary Iran. In P. Alizadeh (Ed.), The Economy of Iran: Dilemmas of an Islamic State, pp. 63-100. I.B. Tauris, London.

Pesaran, M. H. and B. Pesaran (2009). Microfit 5.0: An Interactive Econometric Software Package. Oxford University Press, Oxford.

Pesaran, M. H. and Y. Shin (1996). Cointegration and Speed of Convergence to Equilibrium. Journal of Econometrics 71, 117-143.

Pesaran, M. H. and Y. Shin (1998). Generalised Impulse Response Analysis in Linear Multivariate Models. Economics Letters 58, 17-29.

Pesaran, M. H., Y. Shin, and R. J. Smith (2000). Structural Analysis of Vector Error Correction Models with Exogenous I(1) Variables. Journal of Econometrics 97, 293-343.

Razavi, H. (1982). Optimal rate of oil production for OPEC-member countries. Resources and Energy 4(3), 291 - 305.

Razavi, H. (1983). An analysis of Iran's oil production policy: a welfare maximization approach. Applied Economics 15(2), 243-254.

Sachs, J. D. and A. M. Warner (1995). Natural Resource Abundance and Economic Growth. National Bureau of Economic Research Working Paper Series 5398. 
Sachs, J. D. and A. M. Warner (1997). Sources of Slow Growth in African Economies. Journal of African Economies 6(3), 335-376.

Sachs, J. D. and A. M. Warner (2001). The curse of natural resources. European Economic Review 45(4-6), $827-838$.

Safai, J. (1365, 1986). Development and Estimation of a Macro-econometric Model for the Iranian Economy. M.Sc. Thesis, Shiraz University (in Persian).

Shahshahani-Madani, A. $(1357,1978)$. Econometric Models for Iran and their Applications. Publication of Tehran University (in Persian).

Sims, C. (1980). Macroeconomics and Reality. Econometrica 48, 1-48.

Tornell, A. and P. R. Lane (1999). The Voracity Effect. The American Economic Review $89(1), 22-46$.

Vakil, F. (1973). An Econometric Model for Iran - Estimated Structural Equations. Bank Markazi of Iran Bulletin March-April Issue.

Valadkhani, A. (1997). A Macroeconometric Model for the Iranian Economy. Ph. D. thesis, University of Queensland, Brisbane.

Valadkhani, A. (2006). Unemployment Conundrum in Iran. University of Wollongong Economics Working Paper Series WP 06-15.

van der Ploeg, R. and T. Venables (2009). Symposium on Resource Rich Economies Introduction. Oxford Economic Papers Forthcoming. 